\title{
Utilizing the impact of Earth and atmospheric tides on groundwater systems: A review reveals the future potential
}

\author{
Timothy C. McMillan ${ }^{1,2}$, Gabriel C. Rau ${ }^{1,3}$, Wendy A. Timms ${ }^{4}$, Martin S. Andersen ${ }^{1,5}$ \\ ${ }^{1}$ Connected Waters Initiative Research Centre (CWI), School of Civil and Environmental Engineering, UNSW Sydney, Australia \\ ${ }^{2}$ School of Minerals and Energy Resource Engineering, UNSW Sydney, Australia \\ ${ }^{3}$ Institute of Applied Geosciences, Karlsruhe Institute of Technology (KIT), Karlsruhe, Germany \\ ${ }^{4}$ School of Engineering, Deakin University, Waurn Ponds, Australia \\ ${ }^{5}$ Water Research Laboratory (WRL), School of Civil and Environmental Engineering, UNSW Sydney, Australia
}

\section{Key Points:}

- Earth and atmospheric tides occur globally, are predictable or observable and induce groundwater oscillations under semiconfined conditions

- Tides, in combination with poroelastic theory, enable groundwater system characterization and hydrogeomechanical property quantification

- Analyzing groundwater responses to Earth and atmospheric tides is an underutilized passive technique to quantify subsurface properties 


\begin{abstract}
Groundwater extraction is increasing rapidly in many areas of the world, causing serious impacts such as falling water tables, ground surface subsidence, water quality degradation and reduction of stream baseflow on which many ecosystems depend. Methods for understanding and predicting the impacts of groundwater extraction generally lack detailed spatial and temporal knowledge of the subsurface hydrogeomechanical properties. This review provides a comprehensive understanding of Earth and atmospheric tides and their impact on subsurface pore pressure. First, we evaluate the global occurrence of Earth and atmospheric tides. Then, we illustrate their impact on the groundwater response and connect this with the theory of poroelasticity, which underpins quantitative analyses. Finally, we review methods which utilize these impacts to characterize groundwater systems and to quantify their hydrogeomechanical properties. We conclude by highlighting their potential as passive and low-cost investigation techniques and by outlining the research and developments required to progress and make analyses readily available. Thus, hydrogeomechanical properties of subsurface systems could be obtained at unprecedented spatial and temporal resolution, adding additional value to commonly acquired groundwater and atmospheric pressure data.
\end{abstract}

\title{
1 Introduction
}

Groundwater is the world's largest freshwater resource [Gleeson et al. 2016] and forms the primary water source for billions of people [Gleeson et al. 2012]. However, this vital resource is mainly of fossil origin [Jasechko et al. 2017], rapidly being depleted [Wada et al., 2010 Gleeson et al., 2012], often poorly monitored or quantified [Alley, 2002 [Taylor et al., 2013], and inadequately managed [Famiglietti, 2014]. The potential impacts of such depletion are serious; for example, ecosystem deterioration caused by reduction in baseflow (shift from gaining to losing rivers) [Foster and Chilton [2003], land subsidence (severely damaging infrastructure) [Galloway and Burbey 2011], accelerated inland migration of sea levels and the salinization of freshwater aquifers through saltwater intrusion [Werner et al. 2013].

A much better understanding of subsurface systems (such as groundwater flow and storage changes) must be developed urgently to determine sustainable extraction volumes and minimize the impacts of resource deterioration through adaptive decision making and management [Alley 2002: Aeschbach-Hertig and Gleeson, 2012 Famiglietti, 2014]. In fact, it is the lack of knowledge about hydrogeologic properties on a global scale that prevents coupling of largescale hydrologic models to groundwater reservoirs [Bierkens, 2015]. This problem requires considerably increased effort towards characterizing and quantifying subsurface processes and properties.

Subsurface properties such as permeability and storage coefficients are generally determined using aquifer tests, i.e., by inducing a hydraulic stress (increased or reduced water pressure) in bores specifically designed for this purpose (extraction wells) and analyzing the groundwater response in time and space [e.g., Kruseman and de Ridder, 1990]. Such bores are rare compared to groundwater monitoring bores. These tests require the installation of large capacity groundwater pumps and rely on expert execution and data interpretation. Consequently, aquifer testing results are scarce in both space and time.

By contrast, indirect methods, which are generally based on measuring geophysical properties from the ground surface (e.g., electrical or seismic properties), can cover much larger spatial scales [Binley et al. 2015]. However, these methods also require expert execution, and 
the results are limited by the indirect or ambiguous relationships between the geophysical and hydromechanical subsurface properties. Alternative indirect methods such as remote sensing increase the spatial scales even further; although most of these methods provide interpretations through established relationships, they are limited to the near surface. Subsurface characterization by indirect methods is therefore often qualitative or semiquantitative in the absence of complimentary information, such as from boreholes [Keys, 1989 Deckers et al., 2018]. Consequently, readily deployable and cost-effective methods to increase the rate and scale of directly measured subsurface hydraulic properties are required.
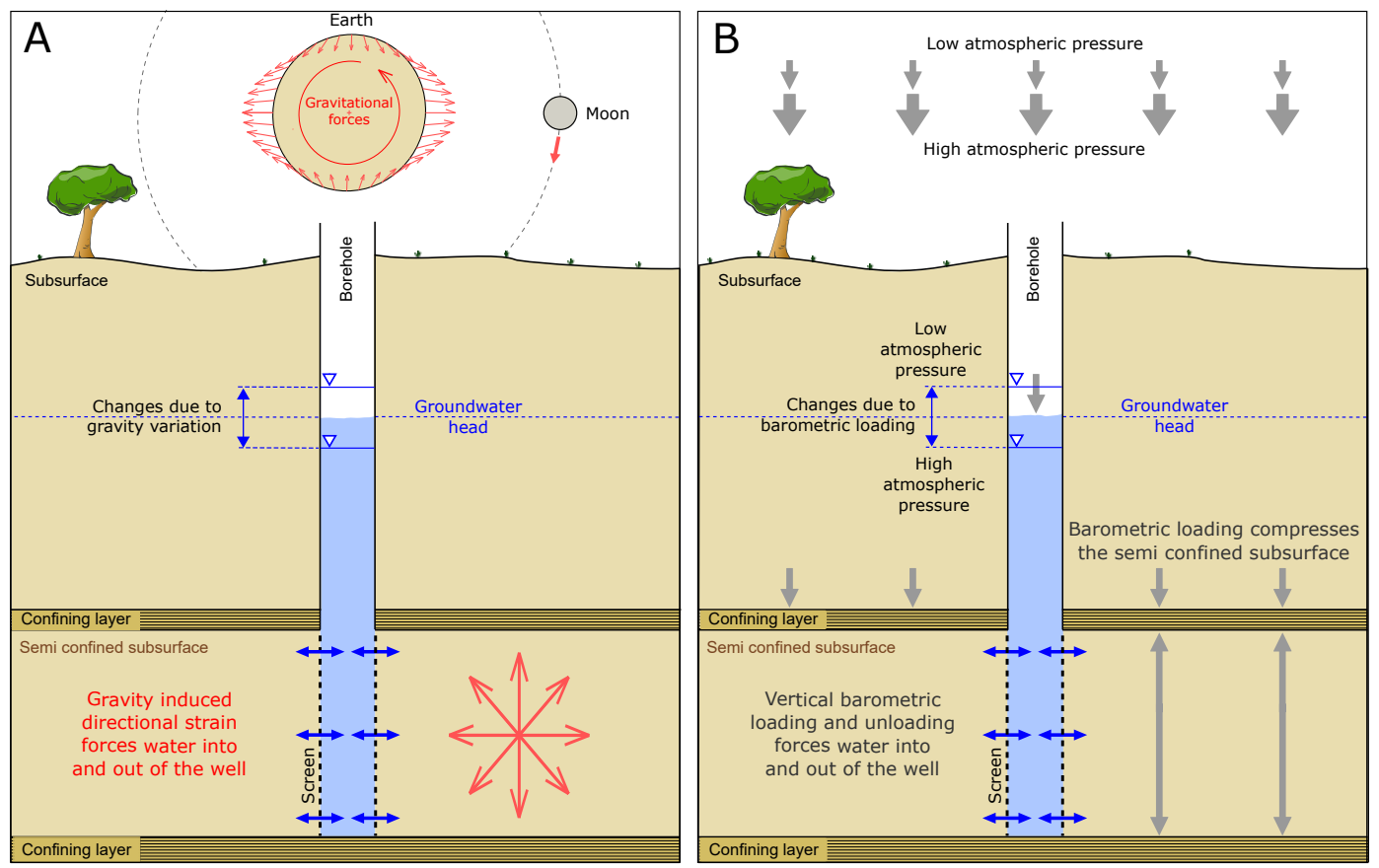

Figure 1: Representation of groundwater pressure head measured in a well penetrating a semiconfined aquifer with a relatively rigid matrix subjected to A) strains caused by Earth tides (using the moon as an example celestial body) and B) barometric loading caused by atmospheric tides.

Boreholes are windows into the subsurface where the groundwater pressure head (also known as borehole water level or standing water level) can be measured. This reflects the average pressure conditions across the vertical subsurface section where the bore screen is located. In situ monitoring equipment, e.g., pressure transducers, are often installed for long-term, and therefore cost-effective, groundwater resource monitoring. Such infrastructure records natural processes that can be investigated through the use of conceptual models. For example, passive investigation methods are advantageous as they rely on directly measuring the response (typically water pressure) to naturally induced stresses within a formation. As an example, the response to moisture loading on the land surface induces subsurface stress resulting in a pore pressure response, which can be used to calculate the hydromechanical properties of a formation van der Kamp and Schmidt 2017]. 
Earth and atmospheric tides (EAT) are naturally occurring and present an ideal opportunity for passive groundwater characterization (note: here, we refer to tides as general forces on the Earth surface, not just limited to the oceans). Figure 1 illustrates how the subsurface is influenced by EAT. The response of groundwater heads to barometric loading (BL) and Earth tides (ET) strains has long been observed and recognized [e.g., Klönne, 1880, Meinzer, 1939 Young 1913]. However, only a few studies have inferred hydromechanical properties mainly from ET signatures [e.g., Bredehoeft 1967, Jorgensen, 1980, Narasimhan et al., 1984 Merritt 2004 Cutillo and Bredehoeft, 2011]. Recently, the work by Allègre et al. [2016] provided estimates of specific storage and permeability by using the identified ET signal response observed in pore pressure data. Similarly, David et al. [2017] used atmospheric pressure fluctuations and ET to calculate specific storage changes associated with the progression of an underground mine over time. In both of these studies, the derived specific storage values were comparable with those obtained through long-term pump tests in either the same or similar locations.

To date, there is limited research regarding tidal impacts on groundwater despite the fact that tidal signatures are ubiquitous. Until recently, a combined approach using both Earth and atmospheric tides has been thwarted by the hurdle of distinguishing tidal influences that act at similar frequencies [e.g., Cutillo and Bredehoeft, 2011, Lai et al., 2013]. However, Acworth et al. [2017] developed a quantitative method that disentangles the effects of tides at similar frequencies and therefore provides an unprecedented opportunity for further development of tidal analysis and characterization of groundwater systems.

In this paper, we summarize how the groundwater response to EAT can be exploited to characterize and quantify subsurface properties. We (1) systematically review EAT impacts on the subsurface, (2) briefly summarize the subsurface poroelastic theory coupled to fluid flow, (3) comprehensively review methods and approaches that use tidal influences to quantify subsurface processes and properties, and (4) illustrate that tidal analysis represents a powerful lowcost technique that is currently underutilized but that requires further research effort to reach its full potential. Finally, we demonstrate that by analyzing decades of accumulated commonly measured variables such as groundwater head and atmospheric pressure, we can obtain unprecedented spatial and temporal knowledge of groundwater system characteristics.

It is important to note that the methods described in this review do not apply to phreatic (zone of saturation beneath the water table) or unconfined aquifers and are only relevant for subsurface layers that show some degree of confinement. Further, we specifically focus on inland systems and explicitly exclude ocean tide influences, which are addressed elsewhere in the literature [e.g., Pugh and Woodworth, 2014].

\section{Earth and atmospheric tides and their subsurface impacts}

Before analyzing the groundwater response to tidal forces, it is useful to consider the existing knowledge about tidal mechanisms and the processes through which they impact the subsurface. A fundamental understanding of EAT requires an inclusion of the scientific disciplines of geodesy, geophysics and atmospheric sciences. The following subsections briefly summarize essential knowledge that relates EAT to its influences on the subsurface.

\subsection{Gravity tides and the tidal potential}

The tidal potential is embedded in gravity $(g)$, which is a constant of acceleration with an average global value of $g=9.81 \mathrm{~m} / \mathrm{s}^{2}$ on the Earth's surface. The unit Gal (after Galileo) 
is also used for gravity, where $1 \mathrm{Gal}$ equals $1 \mathrm{~cm} / \mathrm{s}^{2}$, or $0.01 \mathrm{~m} / \mathrm{s}^{2}$. Gravity can now be measured with a precision of $0.1 \mathrm{~nm} / \mathrm{s}^{2}$ (or $10^{-11} \mathrm{Gal}$ ) either as an absolute or a relative parameter. Van Camp et al. [2017] provide a comprehensive review of gravity measurement techniques.

Tides are commonly associated with periodic changes in ocean levels, perhaps because the oceans fluctuations are clearly visible and affect human activity. One of the earliest concepts to explain the cause of tides can be traced back to Kepler in a letter written to Herwart von Hohenburg in 1607, suggesting that the sea is attracted to the moon through gravity. This explanation was supported by Galileo Galilei's "Discourse on the Tides" written in the year 1616 Naylor 2007 Aiton 1955. However, he focused on observations of the ocean level and did not consider gravitational tides as the cause. The recognition that celestial bodies in motion affect terrestrial gravity can be attributed to Sir Isaac Newton, who first proposed the theory of gravity in his seminal work in the year 1687 [Aiton, 1955].

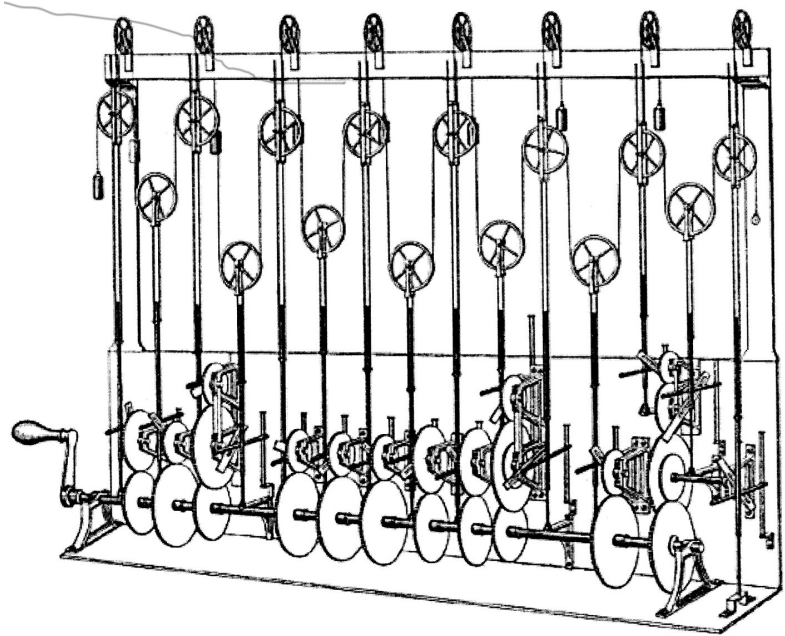

Figure 2: The third tide-predicting machine designed and made by Sir Joseph John Thomson (1879-81) [Thomson, 1881]. The machine translates rotational movements into vertical motion, where a number of different frequencies are added up through a string coupled to circles with different diameters.

Prediction of tides did not occur until centuries later, when Sir William Thomson (also known as Lord Kelvin) designed one of the earliest methods to forecast the tidal signal. Figure 2 shows an example of the tide machine performing harmonic addition using analogue mechanical computations [Thomson, 1881]. Almost in parallel, Sir George H. Darwin delivered a series of lectures about the tides [Darwin 1899]. His monumental work first considered gravity as a dynamic system in which multiple celestial bodies are in relative motion. The Darwinian Symbols used to describe the various tidal components represents a legacy from Thomson [1881] and was later expanded on by Darwin [1899]. These abbreviations are not systematic but have

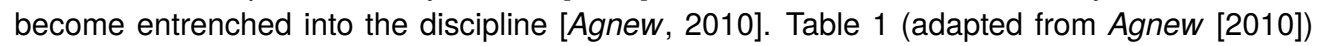
summarizes the Darwin names, frequencies (in 'cycles per day' [cpd]) and different magnitudes of the strongest diurnal and semidiurnal components found in ET. 


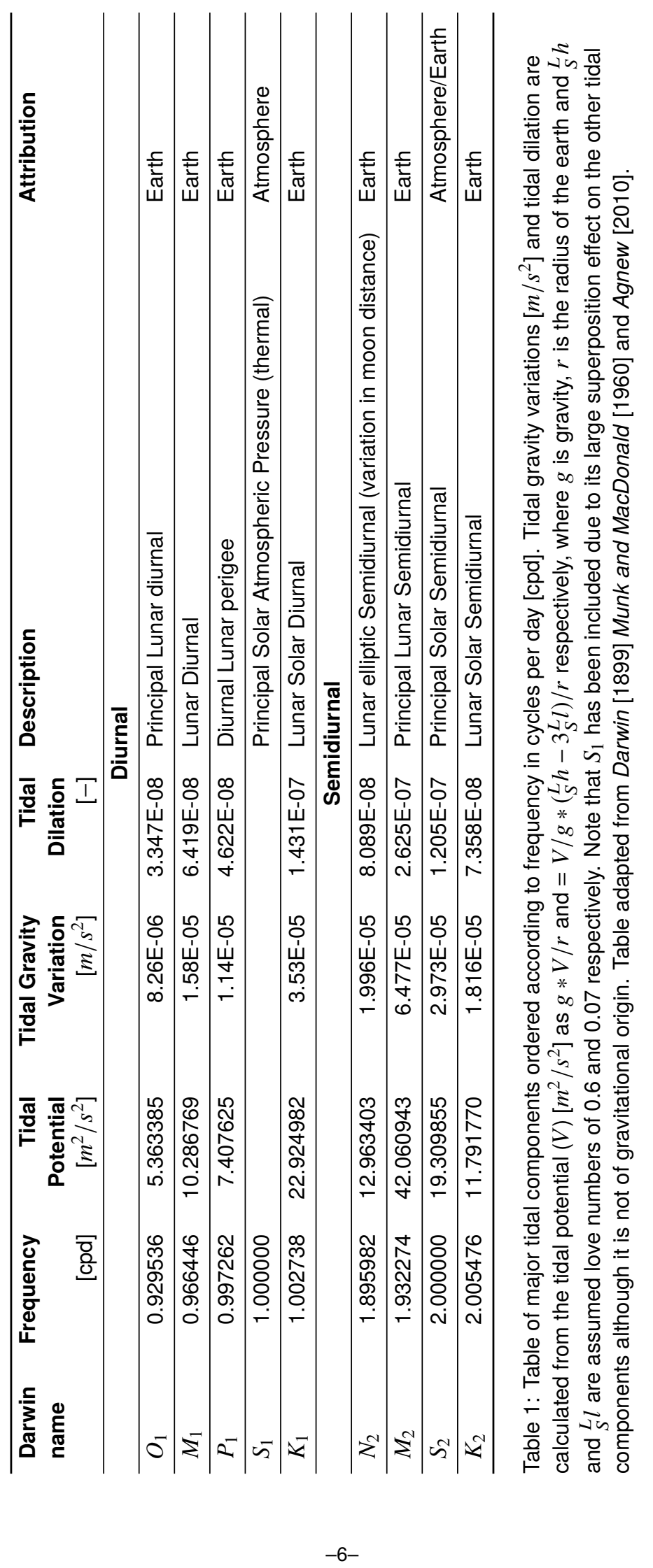


Predicting the tide generating potential is based on calculating the gravitational influence that major celestial bodies such as the sun and moon have on the gravity that exists anywhere on the Earth's rotating surface. Darwin [1899] recognized that the relative movement of planetary bodies and their gravitational influence on Earth can be decomposed into harmonic coefficients and tabulated as a tidal catalog. This work provided the foundation required for predicting the tidal potential. Doodson [1921] noted major discrepancies between predictions and measurements and improved the tidal catalog by increasing the total number of coefficients (Table 2).

\begin{tabular}{|c|c|c|c|c|}
\hline \multirow[t]{2}{*}{ Catalog authors } & \multirow[t]{2}{*}{ Catalog name } & \multirow{2}{*}{$\begin{array}{r}\text { Number } \\
\text { of waves* }\end{array}$} & \multicolumn{2}{|c|}{ RMS Accuracy [nGal] } \\
\hline & & & (time domain) & (freq. domain) \\
\hline Doodson 1921 & - & 378 & $102^{1}$ & $0.34^{1}$ \\
\hline Cartwright and Edden 1973 & - & 505 & $37.4^{1}$ & $0.126^{1}$ \\
\hline \begin{tabular}{|l|l|} 
Büllesfeld 1985 \\
\end{tabular} & - & 656 & $24^{1}$ & $0.08^{1}$ \\
\hline Tamura 1987 & T87 & 1,200 & $6.7^{1}$ & $0.022^{1}$ \\
\hline Xi and Hou 1987 & XI1989 & 2,934 & $7.9^{1}$ & $0.026^{1}$ \\
\hline Tamura 1993 & T93 & 2,114 & $3^{1}$ & $0.01^{1}$ \\
\hline Roosbeek 1996 & RATGP95 & 6,499 & $2^{1}$ & $0.026^{1}$ \\
\hline Hartmann and Wenzel [1995] & HW95 & 12,935 & $0.13^{2}$ & $0.0004^{2}$ \\
\hline Kudryavtsev 2004 & KSM03 & 28,806 & $0.025^{3}$ & $\approx 0.0001^{3}$ \\
\hline
\end{tabular}

Table 2: Overview of tidal catalogs, the number of waves used to calculate the tide generating potential and root-mean-square (RMS) accuracy in the time and frequency domains. *All catalogs were transformed into the HW95 normalization and format by Wenzel [1996] enabling a comparison of the number of waves. ${ }^{1}$ Using a benchmark series in the range from 1970-2029 [Hartmann and Wenzel, 1995]. ${ }^{2}$ Using DE200 ephemerides in a timespan of 300 years [Hartmann and Wenzel 1995]. ${ }^{3}$ Using DE/LE405 ephemerides in the timespan from 1600-2200 [Kudryavtsev, 2004].

Progressive increases in the precision and duration of gravity measurements have yielded ever higher spectral resolution and resulted in increasingly precise decomposition methods and associated detection of even the smallest tidal components. For example, Kudryavtsev [2004] developed the latest tidal catalog (termed KSM03) using Poisson polynomials instead of Fourier coefficients. The KSM03 tidal catalog is based on NASA's calculator for planetary and lunar movement (JPL Development Ephemerides DE405 [Standish 1998]) and is capable of predicting ET with $0.025 \mathrm{nGal}$ in root-mean-square error precision for the time period of 1600 2200. He further illustrated that the maximum difference between the prediction and a benchmark gravity time series decreases with the number of terms from $5 \mathrm{nGal}$ (RATGP95 catalog by Roosbeek [1996] with 6,499 terms) to $0.39 \mathrm{nGal}$ (KSM03 catalog by Kudryavtsev [2004] with 28,806 terms). Table 2 summarizes the tidal catalogs and illustrates their evolution in terms of the number of waves obtained from signal decomposition and the increase in predictive accuracy over time. In essence, the theoretical gravity potential anywhere on Earth can be calculated accurately using geocoordinates (latitude and longitude) as well as time (UTC, or Universal Time Coordinated). 

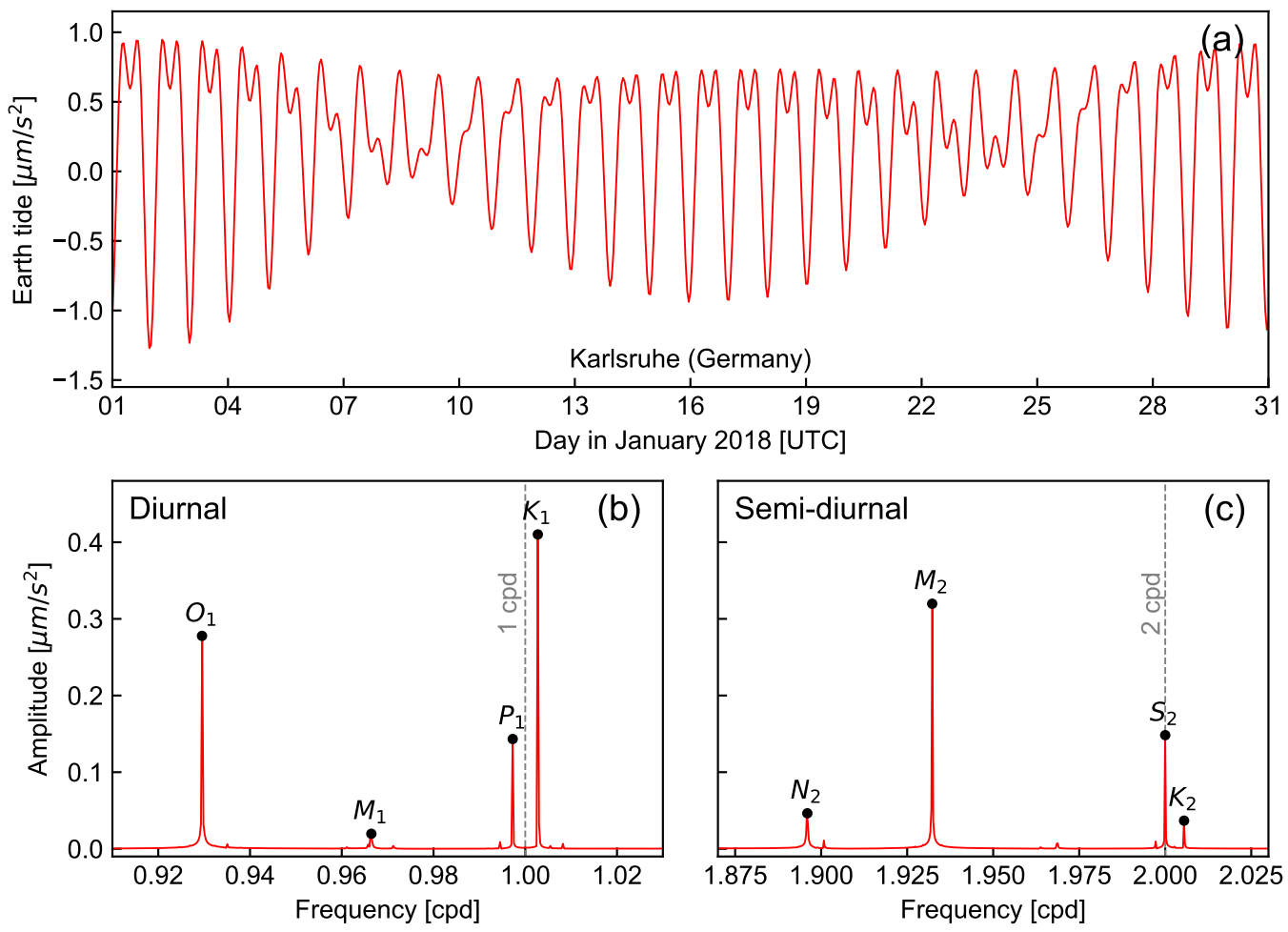

Figure 3: (a) Example of the tidal potential as calculated using PyGTide Rau 2018 (based on ETERNA PREDICT [Wenzel, 1996]) with the latest tidal catalog KSM03 [Kudryavtsev, 2004] for the city of Karlsruhe in Germany (latitude $49.006889^{\circ}$, longitude $8.403653^{\circ}$, height $120 \mathrm{~m}$ ). (b) and (c) show the amplitude spectrum calculated for the same location as above but using a 10-year record for optimal frequency resolution and reported as 'cycles per day' (cpd). Note that in (b), the x-axis is restricted to near $1 \mathrm{cpd}$, whereas in (c), it is restricted to near $2 \mathrm{cpd}$. Major frequency components are labeled using the Darwin convention (see Table 1 .

Software programs are available to predict the tidal potential or to analyze measured gravity time series. Examples include BAYTAP-G [Tamura 1987], MT80W and MT80TW by the International Center for Earth Tides (ICETS, website: http://www.bim-icet .org), GTIDE [Merriam, 1992] and VAV [Venedikov and Vieira, 2004]. Perhaps the most widely used and sophisticated program is ETERNA 3.3, an ET data processing package written in Fortran 77 by Wenzel [1996]. This program contains the subroutine PREDICT to calculate the tidal potential using different tidal catalogs. Kudryavtsev [2004] modified the original code to include the KSM03 tidal catalog, resulting in a new version PREDICT 3.4. This program can be downloaded from the International Geodynamics and ET Service [IGETS 2018].

Another software package is TSoft, which was written for the analysis of time series and ET [Van Camp and Vauterin 2005]. This software includes the capability to synthesize gravity 
tides for any location on Earth. However, it uses the somewhat older tidal catalog by Tamura [1987] and therefore produces gravity potentials with a factor 50 lower precision compared to ETERNA PREDICT in combination with the HW95 catalog (Table 2) Hartmann and Wenzel 1995].

The original ETERNA PREDICT source code has been compiled as a Python module and wrapped into a package named PyGTide [Rau, 2018]. This package provides a convenient approach to easily integrate ET into subsequent scientific computations. Figure 3 shows the ET time series and its amplitude spectrum for the city of Karlsruhe (Germany) calculated using PyGTide [Rau, 2018] with the KSM03 tidal catalog. As expected, the most dominant tidal harmonics are in the diurnal and semidiurnal frequency ranges. These harmonics originate from the moon and sun, which are closest to Earth and therefore exert the strongest gravitational forces (Table 1 .

The above summary illustrates the accuracy with which ET can now be calculated. In fact, a 28-year-long gravity time series measured using superconducting gravimeters was recently compared with calculations from ETERNA in the frequency domain and illustrated excellent agreement [Calvo et al. 2018]. Such predictability has allowed the detection of important Earth processes, for example, of hydrological [Boy et al. 2006 Longuevergne et al., 2009] or atmospheric [Boy et al., 2006] origin, which clearly show up as differences between measured gravity time series and modeled ET.

The availability of tidal prediction software allows geoscientists with no specialist knowledge of astrophysics or geodesy to exploit the gravitational signal, for example, as embedded in groundwater measurements, to quantify subsurface processes and properties on Earth. This constellation of different scientific disciplines enables tidal predictions to be applied to characterize groundwater systems.

\subsection{Tidal response of the solid Earth}

Earth tides (ET) are "the motions induced in the solid Earth, and the changes in its gravitational potential, induced by the tidal forces from external bodies" [Agnew 2010]. Although the average gravity on the Earth's surface is $9.81 \mathrm{~m} / \mathrm{s}^{2}$, the relative movement of celestial bodies causes deviations from mean gravity [Van Camp et al. 2017]. Oscillations due to ET are the largest time-variable signal in gravity measurements at approximately $10^{-7} \mathrm{~m} / \mathrm{s}^{2}$ Xu et al. 2004]. While these fluctuations are harmonic, they occur at different frequencies, which reflect the speed at which celestial bodies move relative to the Earth's reference frame [Doodson. 1921: Melchior, 1974 1983].

Gravitational attraction from celestial bodies exert directional forces in the Earth's crust. Figure 4 shows an example of the tidal force on the Earth (right) as a result of two bodies in relative motion (left) $\mid$ Agnew, 2010]. The subsurface rock mass is elastic and therefore deforms as a result of the force induced from the tide-generating potential. This deformation is referred to as a body tide and can cause a maximum vertical displacement of the Earth's surface of 0.4 $\mathrm{m}$ within the time frame of one day [Krásná et al. 2013].

New methods are now available to measure tide-induced ground surface movements, for example, satellite-based location services such as the Global Positioning System (GPS). Yuan et al. [2013] used data from 456 globally distributed Global Navigation Satellite System (GNSS) receivers spanning a duration of 16 years to quantify the tidal displacement field at the Earth's surface. The authors found that they could calculate horizontal and vertical displacement with 

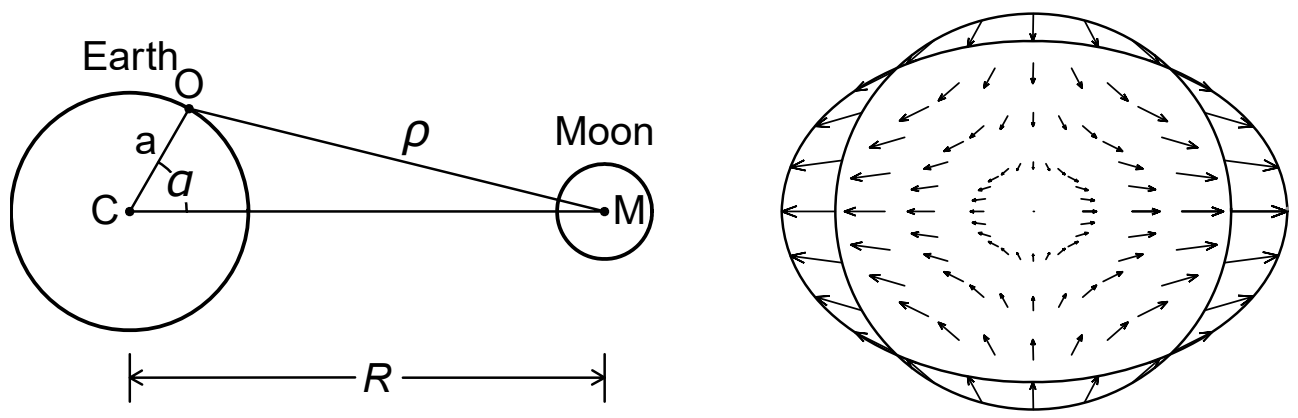

Figure 4: Tidal forcing by Agnew [2010]: (left) an example of the geometry that is considered when the tidal force caused by the moon (centered at M) at a distance $(\rho)$ is calculated for a point $(O)$ on Earth (centered at $\mathrm{C}$ ); $\mathrm{R}$ is the distance between the Earth and moon and $a$ is the radius of the Earth; (right) the resulting tidal force field within the Earth. The scales of the largest force arrows are $1.14 \mu \mathrm{m} / \mathrm{s}$ and 0.51 $\mu \mathrm{m} / \mathrm{s}$, as caused by the moon and sun, respectively. The elliptical line shows the tidally forced equipotential surface. Note that the tidal force field in this illustration is greatly exaggerated.

submillimeter accuracy and identified all major ET components in their analysis. Yuan et al. [2013] also highlighted that their measurements could be used to improve knowledge of the Earth's geomechanical properties.

The forces exerted from ET are multidirectional and dynamic due to the relative motion of celestial bodies in relation to a rotating Earth Agnew, 2010]. Subsurface volumetric deformations are referred to as strains and tilts and can be measured using highly sensitive strain meters [e.g., Agnew, 1986]. Because the tidal potential can be predicted with great accuracy, it can be used to calibrate borehole strain meters to reveal stress from other sources such as earthquakes [Hart et al. 1996].

Although the crust's response to ET can be computed, calculations rely on an appropriate model of the Earth's elastic properties. Love [1911] first analyzed the tidal response of a homogeneous elastic Earth and provided a set of dimensionless values, called the Love-Shida numbers: ${ }_{S}^{L} h$ measures the vertical (radial) displacement of the Earth's elastic properties, ${ }_{S}^{L} k$ is the ratio of the additional potential due to the deformation, and ${ }_{S}^{L} l$ is the ratio of the horizontal (transverse) displacement of an element of crustal mass to that of the corresponding static ocean tide. These numbers were later refined using very-long-baseline interferometry (VLBI), a space geodetic technique using spatially distributed measurements of microwaves from extragalactic sources to quantify relative movements [Krásná et al. 2013].

However, more complex models were needed to describe the heterogeneity of the Earth's internal structure. A radial 1-D distribution of the Earth's elastic properties, named Preliminary Reference Earth Model (PREM), was later provided by inverting globally distributed geophysical measurements [Dziewonski and Anderson, 1981]. The latest analysis by Latychev et al. [2009] used this model as a benchmark for calculating the difference that body tides would cause when considering two different elastic Earth models both with 3-D elastic and density distributions (referred to by the authors as SCRIPPS and SPRD6). Figure 5 shows a global map of the computed maximal difference in radial displacement and surface gravity that the semidiurnal body 

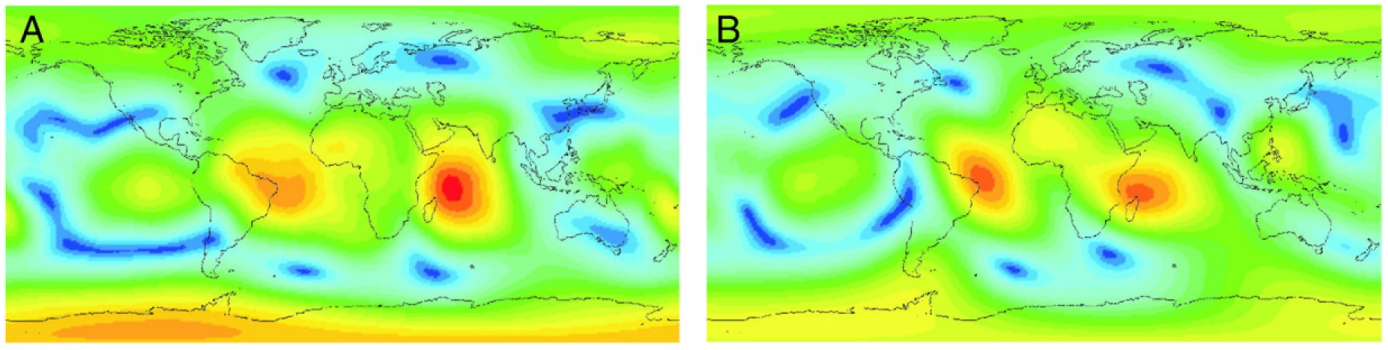

$\begin{array}{lllllllllll}0.0 & 0.1 & 0.2 & 0.3 & 0.4 & 0.5 & 0.6 & 0.7 & 0.8 & 0.9 & 1.0\end{array}(\mathrm{~mm})$
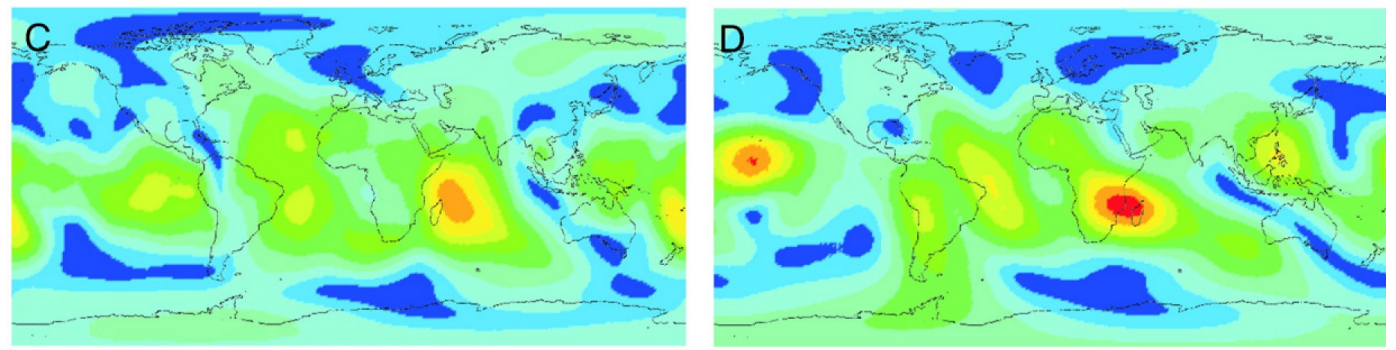

$\begin{array}{lllllllllllll}0.00 & 0.02 & 0.04 & 0.06 & 0.08 & 0.10 & 0.12 & 0.14 & 0.16 & 0.18 & 0.20\end{array}$

Figure 5: Computed response to the tide generating potential in the semidiurnal frequency band using different 3-D Earth models with state-of-the-art knowledge of the crustal properties: maximum of the absolute value of the perturbation in the radial displacement using the 3-D model SCRIPPS $(A)$ and SPRD6 $(B) ;(C, D)$ maximum perturbation in surface gravity using the same models as in $(A)$ and $(B)$. This is Figure 5 from Latychev et al. [2009] and is based on near-maximum gravity values from 8 March 1993 at 14:01.30 UT.

This concise summary of ET demonstrates the enormous complexity involved in the prediction of subsurface effects induced by gravity variations. However, the theory of a poroelastic subsurface, as is outlined in Section 3.1 allows direct quantification of subsurface mechanical properties from observations of variations in pore water pressure combined with computations of the tidal potential.

\subsection{Atmospheric tides}

To the best of our knowledge, the first detailed report of daily and subdaily oscillations in atmospheric pressure was presented by Hann [1889]. They analyzed data from 127 globally distributed barometric stations for amplitudes and phases, with the clear result that amplitudes are largest at the equator and diminish towards the poles. Chapman [1951] also noted their global occurrence and associated them with the term tides, despite their thermal rather than gravita- 
tional origin. Chapman and Westfold [1956] analyzed oscillations in atmospheric pressure on a global scale. They noted that the semidiurnal lunar component is caused by gravity, whereas the solar component is induced by a combination of gravity and thermal expansion of the atmosphere due to solar radiation (insolation). The authors further found that the amplitudes are strongest at the equator, with the solar (denoted as $S_{2}$ ) and lunar (denoted as $M_{2}$ ) component amplitudes quantified as $\approx 150 \mathrm{~Pa}$ and $\approx 6.5 \mathrm{~Pa}$, respectively, and that the amplitudes greatly decrease towards the Earth's poles. While Siebert [1961] noted the complexity of the thermal processes that heating from sunlight causes within the atmosphere, Palumbo [1998] was later able to explain the mystery behind the dominance of the $S_{2}$ component at a frequency of $2 \mathrm{cpd}$ as a result of the harmonic interplay between two complex thermodynamic mechanisms both acting at a frequency of $1 \mathrm{cpd}$. A detailed summary and a quantitative analysis of atmospheric tides (AT) are given by Chapman and Malin [1970].

Clark [1967] was the first to quantify the effects of AT as a barometric efficiency with the aim of isolating the influences from changes in atmospheric pressure on the groundwater head fluctuations. Farrell [1972] then provided a summary of the oscillating pressures induced by AT and how they exert a load on the surface of the Earth, causing stress and elastic deformations in the subsurface. Farrell [1972] then also developed a quantitative model to calculate the tidal loading exerted on the Earth from AT. These subsurface deformations alter the pore pressure and therefore induce fluctuations in groundwater heads, processes which are explored further in Section 3 on the theory of poroelasticity.

The value of detailed AT for groundwater investigations was exploited by Acworth and Brain [2008]. Not only were they able to show the importance of using spectral analysis to distinguish between tidal components, but their investigation of AT also illustrates a strong seasonality in the daily component, whereas the subdaily component appears to be stable over time. Figure 6 shows a 12-year continuous atmospheric pressure record measured on the Liverpool Plains in Australia ( $-31.5^{\circ}$ latitude), and Figure 6(b) illustrates the variation of the time-frequency amplitude content embedded in the atmospheric pressure records [Acworth et al. 2016]. The difference in seasonality of the daily and subdaily tidal components is clearly illustrated with lower relative amplitude in winter time (in the southern hemisphere). As such the subdaily component is more useful for groundwater investigations due to its stability over time. Further discussion of the implications of AT analysis for groundwater is presented in following section regarding the Theory of poroelasticity.

To properly assess the potential use of AT to characterize groundwater systems, their worldwide occurrence and magnitude must be understood. Ray and Ponte [2003] extracted AT from data generated by the European Centre for Medium Range Weather Forecasting (ECMWF) and used these data to analyze the global variation of the $S_{1}$ (diurnal) and $S_{2}$ (semidiurnal) amplitudes and phases. The authors concluded that it is difficult to develop a model to predict their variation. Van Dam and Ray [2010] used this dataset to compute the loading of the solid Earth using Farrell [1972]'s Earth loading model. Figure 7 shows a global map with vertical deformation amplitudes and phases induced by the AT calculated by Van Dam and Ray [2010]'s unpublished tool. The maps illustrate that the strongest subsurface loading occurs near the equator for both $S_{1}$ and $S_{2}$. The maps further illustrate that AT impacts on groundwater systems should be detectable in many large regions around the globe. However, there appears to be a large area of landmass on the northern hemisphere where $\mathrm{BL}$ could be too small to be detected in groundwater heads. Further research is clearly required to determine the threshold for the minimum size of the AT needed for the practical measurement of the groundwater response and its use for quantifying subsurface hydromechanical properties. 

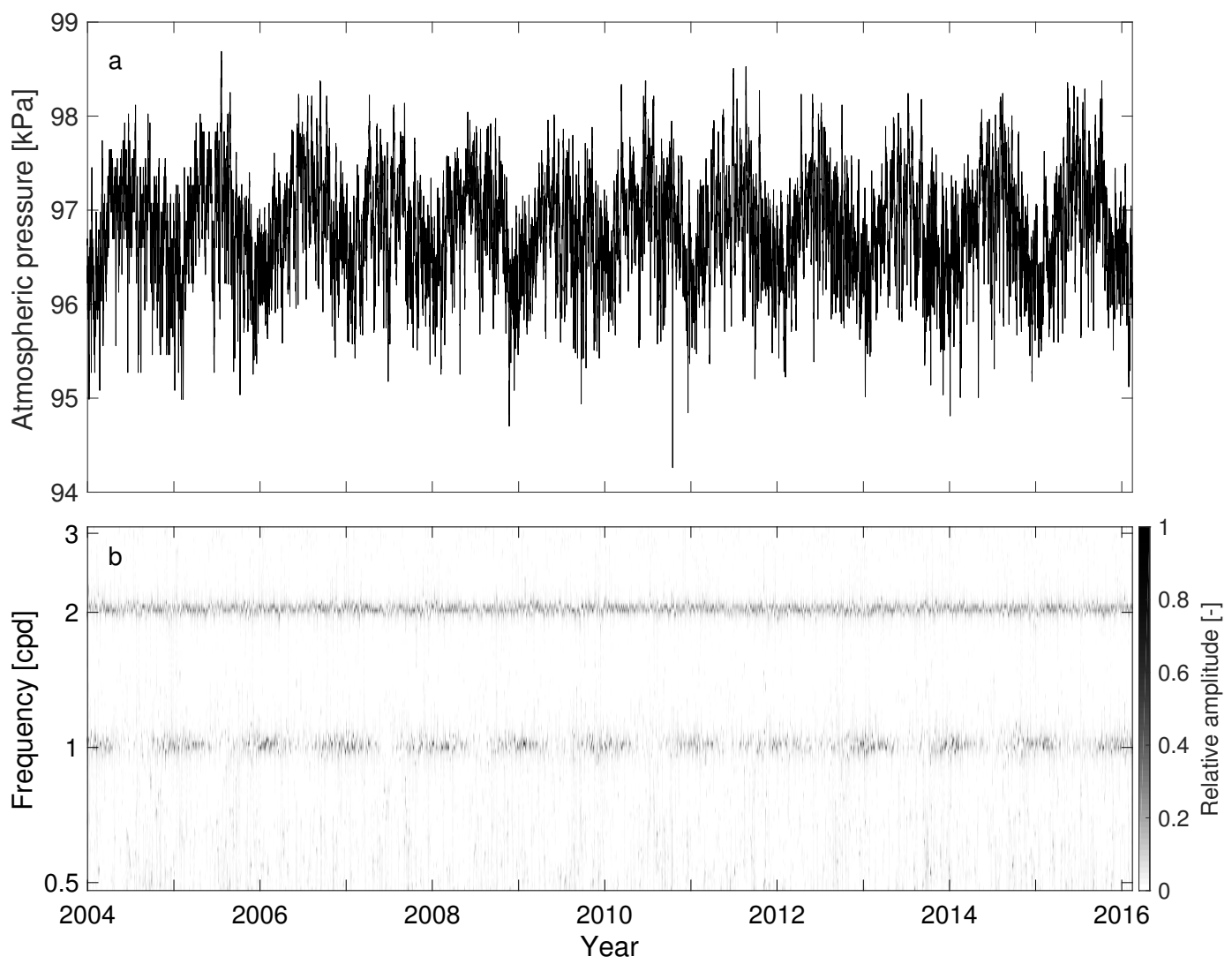

Figure 6: (a) A 12-year continuous atmospheric pressure record measured in Baldry on the Liverpool Plains in New South Wales, Australia and (b) its frequency-time-amplitude content as calculated by the Wavelet Synchrosqueeze Transform [Acworth et al. 2016]. Note the characteristic atmospheric tides at frequencies of 1 and $2 \mathrm{cpd}$.

Our synthesis of the occurrence, spatiotemporal distribution and effect that AT have on the solid Earth demonstrates their potential as a natural subsurface stress. In addition, atmospheric pressure has now been recorded for over 100 years as part of routine weather monitoring. In the last couple of decades, atmospheric pressure has also been measured routinely to correct the absolute pressure measurements of groundwater heads when unvented pressure transducers are used for routine monitoring. This widespread monitoring of atmospheric pressure means that for large regions of the globe, there would be a robust basis for 'data mining', i.e., analyzing decades of existing groundwater pressure datasets for their tidal signals, which could then be used for unprecedented spatial and temporal groundwater system characterization. 

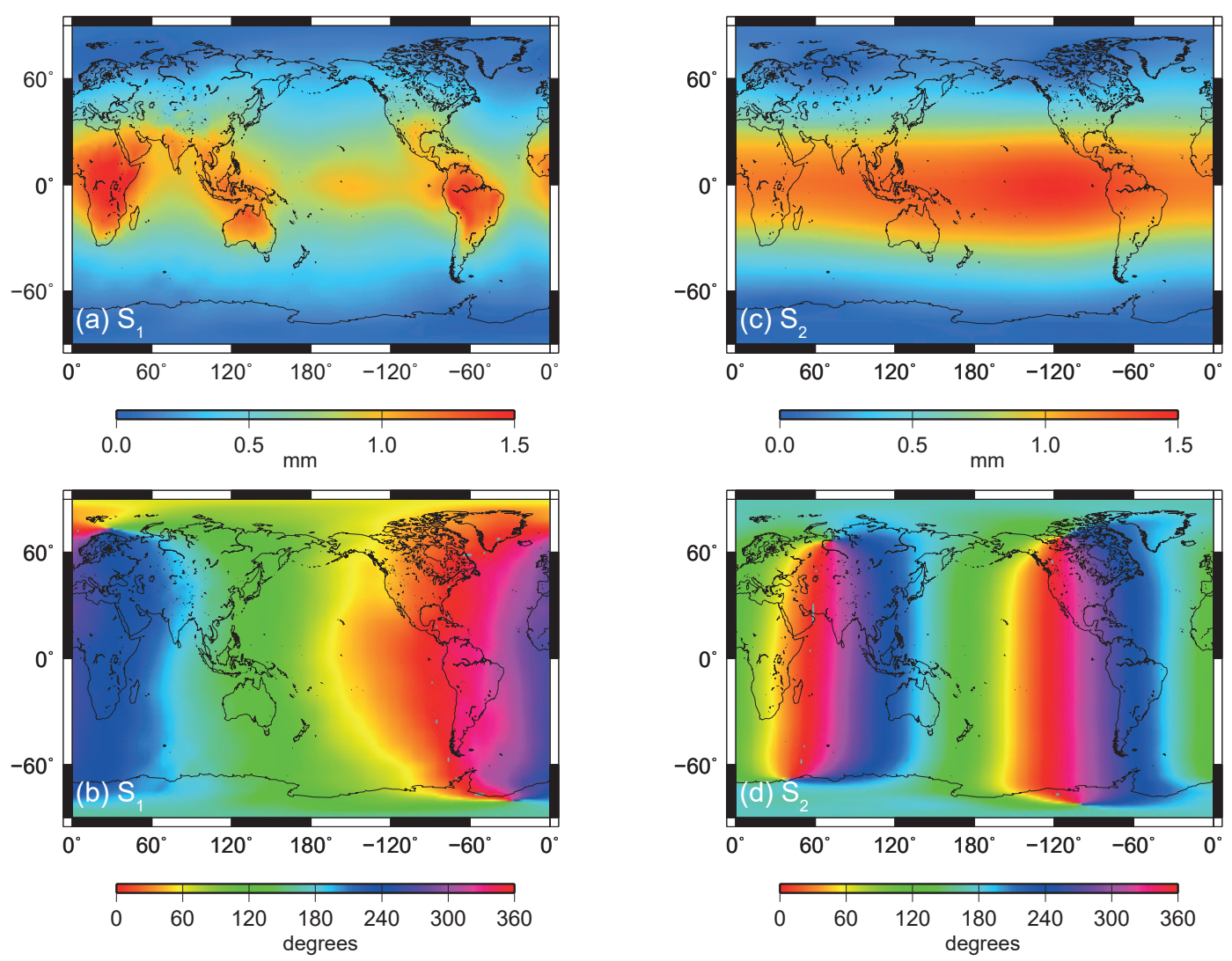

Figure 7: Results from a model predicting the amplitudes and phases of radial surface displacement to the Earth caused by loading from atmospheric tides (a-b: $S_{1}$ at $1 \mathrm{cpd}, \mathrm{c}-\mathrm{d}: S_{2}$ at $2 \mathrm{cpd}$ ) on a global scale [Van Dam and Ray, 2010]. The $S_{1}$ and $S_{2}$ amplitudes are derived from Ray and Ponte [2003], and the loading is calculated using the elastic Earth model by Farrell [1972] using the center of earth as the reference frame.

\section{The saturated poroelastic subsurface}

\subsection{Early observations of subsurface poroelasticity}

Traditional hydrogeological investigations (such as aquifer tests) assume that the aquifer matrix is rigid. However, in order to understand EAT influences on groundwater systems, a theory allowing the elastic deformation of both rocks and water must be invoked. Elasticity of aquifers was first recognized in the early $19^{\text {th }}$ century through the works of Meinzer and Hard [1925] and Meinzer [1928], who recorded the compression of the North Dakota Sandstone associated with extraction of water from a confined aquifer. Although not explicitly stated, Meinzer and Hard [1925] described the principles that we now refer to as specific storage in confined groundwater systems. Theis [1935] later explicitly described the coefficient of specific storage and introduced pump testing as a direct method to quantify aquifer properties. 


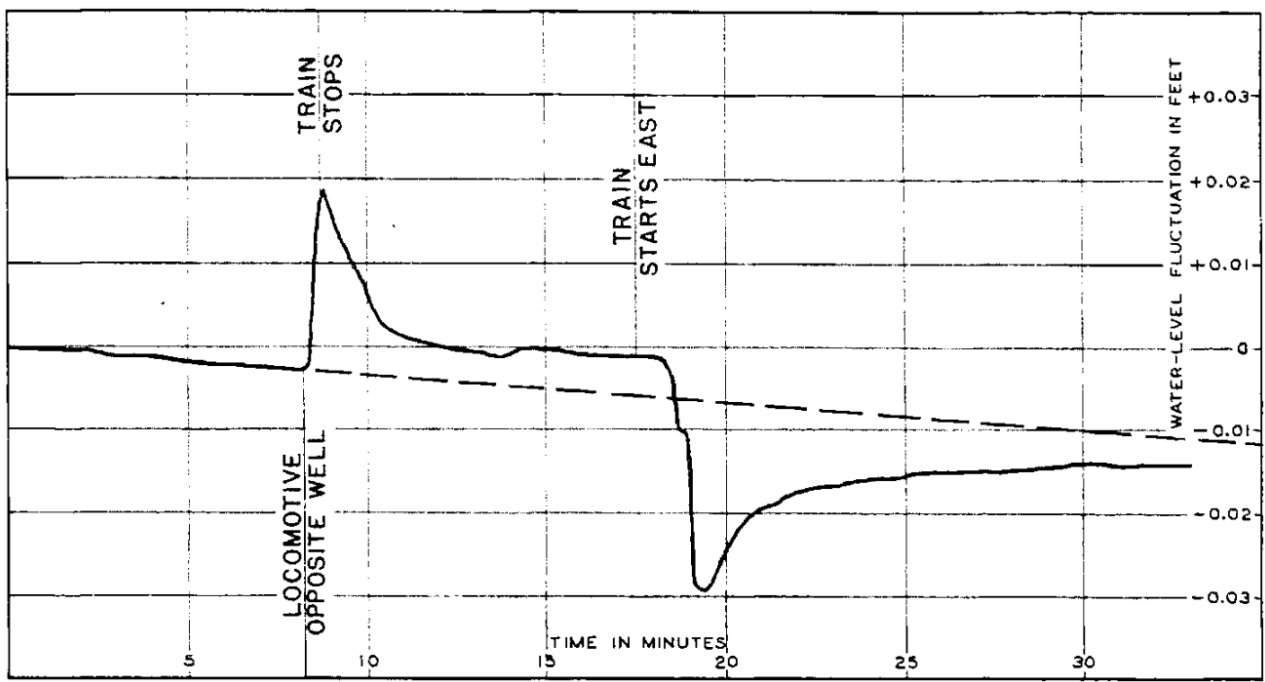

Figure 8: Groundwater head fluctuations in a well produced by a passing freight train Jacob, 1939]. Note the rapid loading/unloading and subsequent flow of water away from and towards the zone of stress when the train arrives and departs, as indicated by the exponential change in groundwater head towards equilibrium.

Jacob [1939] recorded fluctuations within groundwater piezometers due to surface loading and unloading from a passing locomotive and thereby confirmed the fact that aquifers are elastic. Figure 8 shows this original observation as annotated by the author. Biot [1941] first developed a comprehensive 3-D mathematical and physical theory for consolidation, which now forms the foundation upon which state-of-the-art poroelastic theory is based.

\subsection{Stress, strain and pore pressure changes in porous and water saturated forma- tions}

The effects of changes in stress, strain and pore pressure in porous and water saturated formations is quantified by the theory of poroelasticity. This theory describes the elastic strain response of a fluid-solid coupled porous material when it is subjected to an external force. It also describes how the strain from this external force is distributed between the fluid and solid as an increase in pore pressure, elastic deformation of the skeletal matrix or, more often, a combination of both. It should be noted here that the theory of poroelasticity is considered from different perspectives by various scientific and engineering disciplines. For example, soil scientists and rock engineers mostly focus on the solid matrix and prediction of processes such as consolidation [Verruijt, 2013]. Geophysicists, mining and reservoir engineers take a more comprehensive approach by considering the detailed coupling between the fluid and the matrix. Hydrogeologists are primarily focused on aquifer-aquitard properties related to water storage and transmission and how they can be quantified from observed groundwater head fluctuations [Domenico and Schwartz 1997]. 
There are also some differences in terminology between these disciplines. For example, deformation or Young's modulus used in geotechnical engineering is also known as the elastic modulus among hydrogeologists. This modulus describes the ratio of stress to strain, where tension or compression occurs along an axis. However, some key moduli, such as Poisson's ratio, are consistent between the fields. Poisson's ratio describes lateral strain divided by axial strain, describing the compression that occurs transverse to stretching in a material. It is important to note that in all of the disciplines, these moduli are regarded as properties of the rock mass and may not be representative of local-scale features, such as individual fractures [Galvin, 2016].

Wang 2001] provides a comprehensive summary of the theory behind linear poroelasticity, which links across the disciplines. We summarize this work and other seminal references regarding saturated formations and groundwater flow, followed by consideration of undrained versus drained response to stress and strain. To do so, we must first outline the principles of linear poroelasticity when coupled to the concept of fluid continuity, as this is required to gain hydromechanical understanding from the pore pressure response to tidal forces. Much of this work is based on the ground-breaking research by Biot [1941]. According to Wang [2001], the word poroelasticity first occurred in the context of research regarding petroleum production by Geertsma [1966]. Poroelasticity assumes a porous material in which the pore space is entirely saturated with a fluid (water in our context) and where both the solid skeleton and the fluid are compressible when stress is applied. It is generally assumed that this relationship is linear [Wang 2001], which is a reasonable assumption for tidal forces where the change of stress is small.

We summarize the basic poroelastic theory and its coupling to water flow and storage as is comprehensively outlined in Jorgensen [1980] and Wang [2001]. Four basic variables describe a poroelastic problem:

1. A stress tensor, depicted as $\overline{\bar{\sigma}}$ with entries $\sigma_{i j}$,

2. A strain tensor, depicted as $\overline{\bar{\epsilon}}$ with entries $\epsilon_{i j}$,

3. A pore pressure scalar, depicted as $p$,

4. An increment of fluid content scalar, depicted as $\xi$.

If principle coordinates are used, then the shear stress and strain components $\left(\sigma_{i j}\right.$ and $\left.\epsilon_{i j}\right)$ are zero for $i \neq j$ reducing both tensors to vectors $(\bar{\epsilon}$ and $\bar{\sigma})$. In addition, the tensor with poroelastic constants becomes symmetric. Consequently, the basic coupling of the above variables can be written as

$$
\bar{\epsilon}=\frac{1}{E}\left[\begin{array}{ccc}
1 & -v & -v \\
-v & 1 & -v \\
-v & -v & 1
\end{array}\right] \cdot \bar{\sigma}+\frac{1}{3 H} p
$$

and

$$
\xi=\frac{1}{3 H}\left(\sigma_{1}+\sigma_{2}+\sigma_{3}\right)+\frac{1}{R} p
$$

where $v$ is the drained Poisson ratio, $E$ is the drained Young's modulus, $1 / R$ is the unconstrained specific storage coefficient, and $1 / H$ is the poroelastic expansion coefficient.

These relationships rely on the standard linear elastic equation

$$
K=\frac{E}{3(1-2 v)}=\frac{1}{\beta}
$$


where $K$ is the bulk modulus $[\mathrm{Pa}]$ of the subsurface formation. Note that the bulk modulus is generally the reciprocal of the compressibility $\beta$. Some of the coefficients used can further be defined as follows: $1 / H$ is the poroelastic expansion coefficient

$$
\frac{1}{H}=\frac{1}{K}-\frac{1}{K_{S}},
$$

where $1 / K_{s}$ is the bulk solid grain (or unjacketed) compressibility $\left[\mathrm{Pa}^{-1}\right]$. This is a measure of the reduction of bulk volume of the solid grains and is not well defined for grain mixtures WWang 2001]. Further, $1 / R$ is the unconstrained specific storage coefficient defined as

$$
\frac{1}{R}=\left(\frac{1}{K}-\frac{1}{K_{s}}\right)+\theta\left(\frac{1}{K}-\frac{1}{K_{\theta}}\right),
$$

where $\theta$ is the total porosity of the formation [-]. The unjacketed pore compressibility $1 / K_{\theta}$ can be expressed as

$$
\frac{1}{K_{\theta}}=-\frac{1}{\theta}\left[\frac{\alpha}{K B}-\frac{\theta}{K_{w}}-\frac{\alpha}{K}\right],
$$

where the compressibility of water is $1 / K_{w}=\beta_{w} \approx 4.58 \cdot 10^{-10} \mathrm{~Pa}^{-1}$. In Equation 6 the BiotWillis coefficient can be stated as

$$
\alpha=\frac{K}{H}=1-\frac{K}{K_{s}},
$$

and the Skempton coefficient is

$$
B=\frac{R}{H} \text {. }
$$

Equations 1 to 8 provide the complete set of coefficients and relationships required to quantify stress, strain and pore pressure in subsurface formations.

The assumption of isotropic stress conditions will turn the stress and strain tensors into scalars and define the stress as the negative of a confining pressure $\sigma=-p_{c}$. This significantly simplifies Equation 1 to

and Equation 2 to

$$
\epsilon=\frac{1}{K} \sigma+\frac{\alpha}{K} p,
$$

$$
\xi=\frac{\alpha}{K} \sigma+\frac{\alpha}{K B} p .
$$

The assumption of isotropic stress is often sufficient for smaller scales relevant to the analysis of borehole pore pressure data.

It is important to note that the poroelastic equations described above are simple generalizations of linear elasticity. This linear relationship holds until the point where elastic deformation transition into plastic deformation or brittle deformation such as fracturing of cemented geological material. However, due to the relatively small stresses induced from tidal forces, this linear relationship is a reasonable assumption.

\subsection{Coupling stress, strain and pore pressure to groundwater flow}

In general, a change in subsurface stress results in a pore pressure response. A localized stress induces a spatial pressure gradient, which will cause subsurface water flow. The fluid 
flow is quantified using Darcy's Law

$$
\bar{q}=-\frac{k}{\mu} \nabla p,
$$

where $\bar{q}$ is the flow vector $[\mathrm{m} / \mathrm{s}], k$ is intrinsic permeability $\left[\mathrm{m}^{2}\right]$ of the subsurface material, and the dynamic viscosity for water is $\mu \approx 1.002 \cdot 10^{-3} \mathrm{~kg}(\mathrm{~m} \mathrm{~s})^{-1}$. Naturally, the continuity of fluid must then also be given

$$
\frac{\partial \xi}{\partial t}=-\nabla \cdot \bar{q},
$$

where $t$ is time $[s]$. Substituting Darcy's Law (Equation 11 into the continuity equation (Equation 12 yields the general differential relationship for groundwater flow and storage changes:

$$
\frac{\partial \xi}{\partial t}=\frac{k}{\mu} \nabla^{2} p+Q
$$

where $Q$ is a fluid source or sink. This can further be combined with the isotropic poroelastic relationships (Equations 9 and 10 ) and results in the general description of coupled flow and poroelasticity for stress

$$
\frac{\alpha}{3 K} \frac{\partial \sigma_{k k}}{\partial t}+\frac{\alpha}{K B} \frac{\partial p}{\partial t}=\frac{k}{\mu} \nabla^{2} p+Q
$$

and strain

$$
\alpha \frac{\partial \epsilon_{k k}}{\partial t}+\frac{\alpha^{2}}{K^{u}-K} \frac{\partial p}{\partial t}=\frac{k}{\mu} \nabla^{2} p+Q .
$$

Here, the undrained bulk modulus can be expressed as

$$
K^{u}=\frac{K}{1-\alpha B},
$$

where all parameters have previously been defined. Note here that the superscript $u$ stands for undrained conditions, a concept that is explained in Section 3.4

In the context of tidal influences on groundwater systems, we can further simplify this theory by assuming local horizontally homogeneous conditions and that wells provide a point-inspace pressure measurement representative of the formation in which they are screened (see Figure 1). Therefore, horizontal variations in subsurface properties can be neglected, and the description reduces to $1 \mathrm{D}$ in the vertical direction. This treatment significantly reduces Equations 14 and 15 to

$$
S_{s}^{v} \frac{\partial p}{\partial t}=\frac{k}{\mu} \nabla^{2} p+Q
$$

where $S_{s}^{\nu}$ is the uniaxial (vertical) specific storage $\left[\mathrm{ms}^{2} / \mathrm{kg}\right]$ expressed as pore pressure change given as

$$
S_{s}^{v}=\frac{S_{s}}{\rho_{w} g}
$$

and where $S_{S}$ is the specific storage $\left[\mathrm{m}^{-1}\right]$, the water density is $\rho_{w} \approx 998 \mathrm{~kg} / \mathrm{m}^{3}$, and the gravitational constant is $g \approx 9.81 \mathrm{~m} / \mathrm{s}^{2}$. Equations 17 and 18 are commonly used in hydrogeology to model flow and storage changes, especially in response to hydraulic stresses such as pumping.

It is interesting to note that the left-hand side of both Equations 14 and 15 expresses the extended storage term that links pore pressure to stress and strain, whereas the right-hand side can be viewed as the movement of the pore fluid in response to pressure changes. 
The above summary contains a number of rock mechanics or geotechnical parameters and relationships. Within the scope of this paper, we illustrate that through existing published work, such parameters can be calculated from the pore pressure response to tidal forces. We believe that further research in this field can develop a better understanding of subsurface processes and estimation of properties using these relationships.

\subsection{Undrained versus drained groundwater response to stress and strain}

The theory of poroelasticity defines two end-members depending on whether fluid flow can occur as a response to stress, referred to as drained or undrained conditions. Whether a response to stress is drained or undrained will depend upon the rate at which the stress is applied in relation to the rate at which the system is able to re-equilibrate via flow in response. Poroelastic coefficients represent undrained conditions if the loading occurs faster than the system can respond, i.e., constant mass of water over time $(d \zeta / d t=0$, where $\zeta$ is a mass increment). By contrast, drained poroelastic conditions occur for slow loading and when the physical properties of the subsurface allow water to redistribute in response, i.e., resulting in a constant pore pressure over time $(d p / d t=0)$. According to common practice and within this work, undrained parameters are denoted with the superscript $(u)$, whereas no suffix is used for drained conditions [Rice and Cleary 1976, Domenico and Schwartz, 1997 Wang 2001].

It is important to note that the meaning of drained in this context does not refer to water draining from the pores to create unsaturated conditions, as is often used in hydrogeology. Instead, this term refers to how fast a pressure wave propagates in response to stress under saturated conditions. For rapid loading such as that of a train moving on top of an aquifer, there is insufficient time for water to flow as a result of the increased stress and the pore pressure rises. This fact is demonstrated by the first response of the pore pressure to the stress of the incoming train in Figure 8. Because the stress remains, drainage occurs as a result of the locally increased pore pressure, which causes a hydraulic gradient and consequently leads to flow away from the stressed zone (Equation 11.

The subsurface response to EAT is generally considered as undrained. This consideration is because the stress changes exerted by tides apply uniformly over a horizontal distance that is larger than the scope of investigation [Cutillo and Bredehoeft, 2011] and because of the relatively fast changes in stress. Consequently, there is no horizontal hydraulic gradient and therefore no flow either. However, these assumption have not been verified in the literature.

The implication of drained or undrained conditions can be best explained through the examination of their effects on the Poisson's ratio. The undrained Poisson's ratio can be denoted by

$$
v^{u}=\frac{3 v+\alpha B(1-2 v)}{3-\alpha B(1-2 v)},
$$

whereas the drained Poisson's ratio is

$$
v=\frac{3 v^{u}-\alpha B\left(1+v^{u}\right)}{3-2 \alpha B\left(1+v^{u}\right)}
$$

The undrained Poisson's ratio is larger than that of the drained Poisson's ratio as an increase in fluid pressure decreases the unconstrained lateral and vertical strains [Wang, 2001]. 


\subsection{Example poroelastic parameter values for typical subsurface systems}

As demonstrated by the theory of poroelasticity presented in Sections 3.2 and 3.3 understanding elastic geomechanical variables is essential for interpretation of hydromechanical parameters. When these elastic values are unknown, it is common practice to use literature values from a similar lithology, such as those presented in Table 3 . These assumed values are often a considerable source of uncertainty within calculations and numerical models. For example, within Table 3 part (D) two different sets of values are presented for the same stratigraphic unit (Hawkesbury Sandstone), where, depending on the literature source used, the results of a hydromechanical assessment would vary considerably [Bertuzzi, 2014 Zhang et al. 2018].

\section{Impacts of Earth and atmospheric tides on groundwater systems}

\subsection{Groundwater response to tidal forces}

The first observations of tidal influences on groundwater can be traced back to Klönne [1880], who recorded fluctuating water levels and atmospheric pressure in a flooded mine in Germany. Young [1913] later meticulously recorded groundwater head fluctuations in inland artesian wells in South Africa and identified frequency components that are attributable to both AT and ET influences. Robinson [1939] investigated wells in lowa, USA, and revealed that the fluctuations correspond to the moon's cycle and the Earth's rotation. George and Romberg [1951] graphically correlated the groundwater head in an artesian well with atmospheric pressure and gravity measurements and computed tidal forces. These early results clearly demonstrated that EAT measurably impact groundwater heads. Figure 9 illustrates one of the earliest recordings in which the influence of tides on groundwater is evident [Meinzer, 1939].

Both BL and ET analysis rely on high-frequency pore pressure measurements and the subsequent analysis of concurrent periodic signals from external forcing. Both approaches have been in development since the mid-20th century with the recognition that pore fluid pressure variations are partly a response to externally imposed stress changes [Jacob 1940, Ferris 1952]. The induced stress from $B L$ is in principle described by Figure 9 [Meinzer [1939].

Bredehoeft [1967] noted that groundwater heads in most artesian (a hydrogeology term synonymous with confinement) wells should fluctuate in response to ET. He provided the first quantitative analysis of a formation's specific storage and porosity by exploiting such fluctuations. Melchior [1974] reviewed ET and postulated that underground reservoir properties could be calculated from well responses because the inducing potential is accurately known. Several works have extended previous methods to also calculate the aquifer transmissivity [e.g., Hsieh et al. 1987, 1988]. Analyzing the groundwater response to ET has recently gained momentum as a practical method to estimate aquifer permeability and specific storage [Merritt, 2004, Cutillo and Bredehoeft 2011, Burbey et al., 2012, Xue et al., 2013; Allègre et al., 2016]. In the following subsections, we comprehensively review these works and integrate their findings.

\subsection{Groundwater response to Earth tide strains}

As demonstrated above, ET cause subsurface strains within groundwater systems as pressure fluctuation (see Equations 9 and 10, which can be monitored. The first use of these responses for the purpose of characterizing subsurface hydromechanical properties was conducted by Bredehoeft [1967], who were able to identify a relationship between tidal groundwater head fluctuations as being related to the specific storage of the monitored aquifer. Earlier 

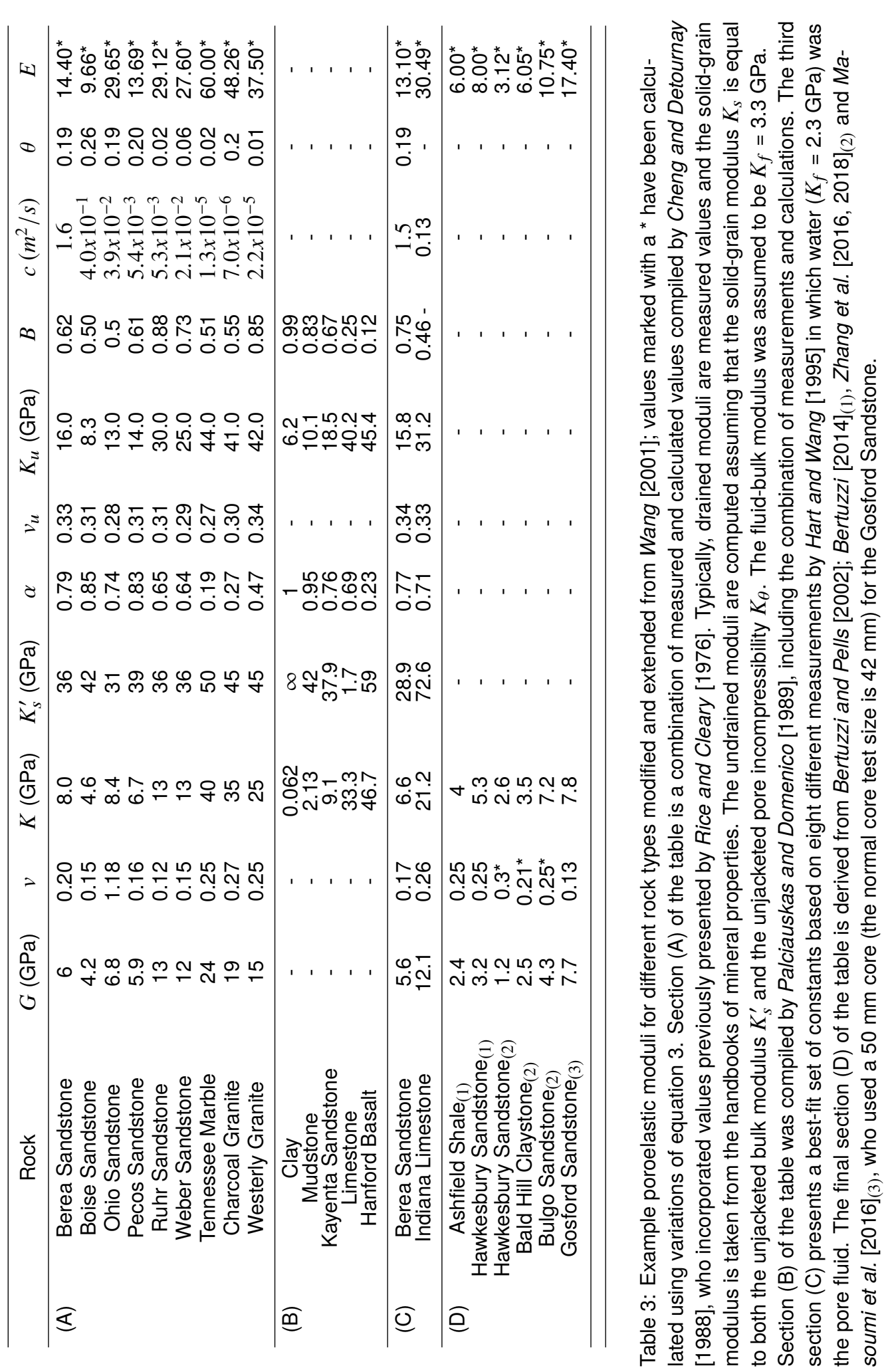

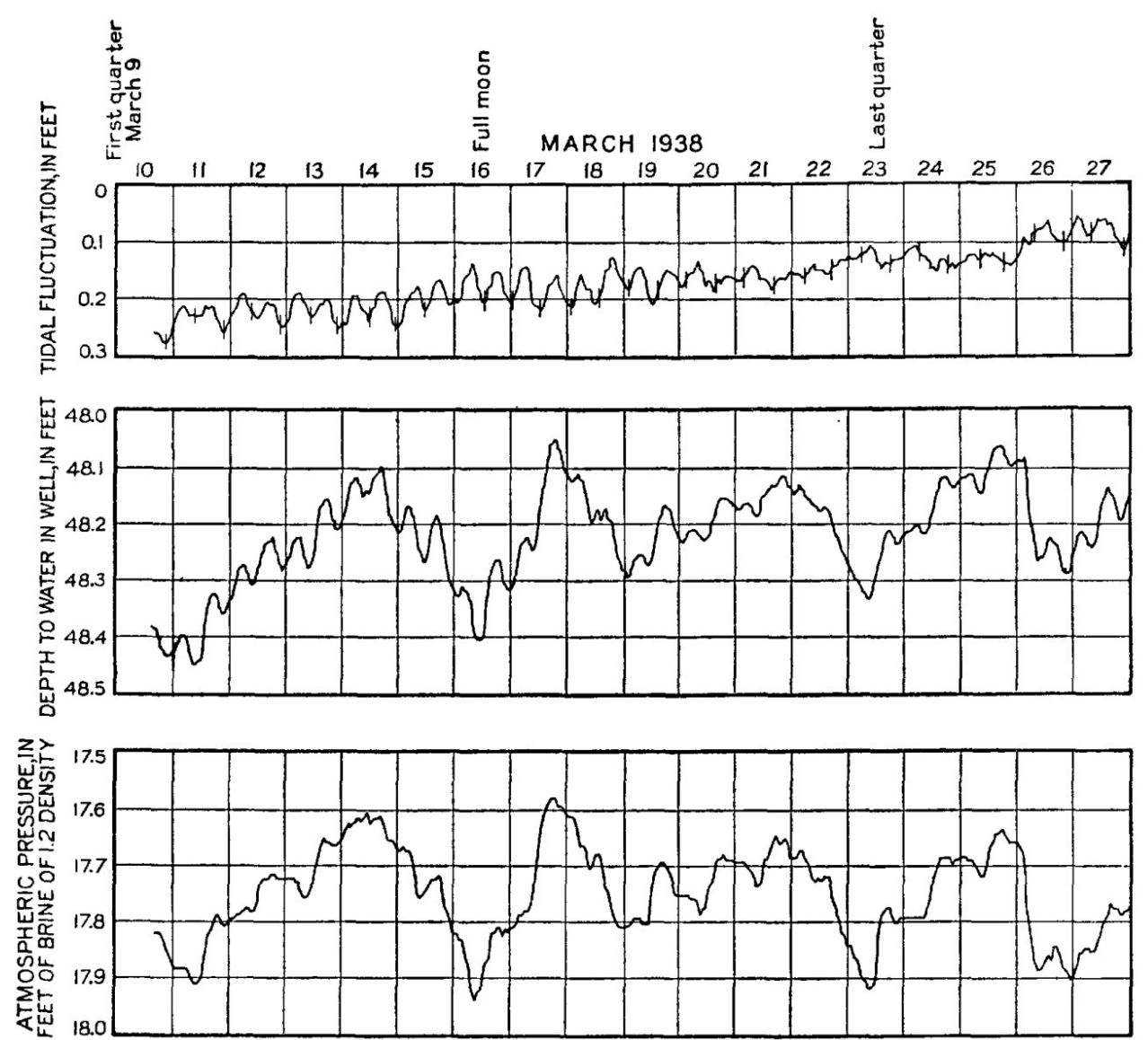

Figure 9: Response of groundwater heads to Earth and atmospheric tides (Figure 40 in Meinzer 1939]). Note how the depth to water (middle panel) reflects both the high-frequency Earth tides (top panel) and lower-frequency atmospheric fluctuations (bottom panel). Note further that the second panel is the depth to the groundwater level, i.e., the inverse of the pore pressure for open boreholes.

work using ocean tides rather than ET for subsurface characterization by authors such as Ferris [1952 had focused on loading and unloading effects of changes in sea level, in addition to the development of the theory of poroelasticity. It was also the work by Bredehoeft [1967] that established that it was possible to calculate not only the specific storage of aquifers but also the porosity if the Poisson's ratio was known.

Further development came in the form of an analytical solution by Robinson and Bell [1971], who quantified the various harmonic components present within the ET signal and successfully inferred specific storage and porosity. Robinson and Bell [1971] highlighted inaccuracies due to the uncertainty in the bulk modulus particularly associated with coastal monitoring wells. der Kamp [1972] attempted to solve the issue of calculating aquifer hydraulic diffusivity from these coastal wells. The accuracy of this attempt was later questioned when Merritt [2004] tried to 
replicate observations and results using the der Kamp [1972] solution compared to Li and Jiao [2001]'s solution, which produced much higher transmissivities.

It was not until a decade later that significant progress was made by both van der Kamp and Gale [1983] and Domenico [1983], who properly accounted for not only the compressibility of water but also the compressibility of the grains (note here the grains as opposed to matrix) within the aquifer due to their elastic nature. These considerations allowed for relating the specific storage and porosity, as shown in Equation 21 and Equation 22 [van der Kamp and Gale, 1983 Cutillo and Bredehoeft, 2011]. As with the previous works, van der Kamp and Gale [1983]'s solution still required the assumption that any aquifer is homogeneous, laterally extensive and of a porous nature. This methodology was supported experimentally by Narasimhan et al. [1984], who compared results of specific storage from ET tide analysis with those achieved from pump tests at the same locations. Narasimhan et al. [1984] also made key recommendations suggesting the use of longer monitoring periods, packers to seal of sections in open wells (later explored further by Cook et al. [2017]) and an integrated approach using both ET and BL. This treatment would allow for the integration of variables that can be directly calculated and thus reduce errors that are introduced by assumed values as discussed in Subsection 3.5 .

The specific storage from van der Kamp and Gale [1983] is given as

$$
S_{s}=\rho g\left[\left(\frac{1}{K}-\frac{1}{K_{s}}\right)(1-\lambda)+\theta\left(\frac{1}{K_{w}}-\frac{1}{K_{s}}\right)\right],
$$

where

$$
\lambda=\alpha \frac{2(1-2 v)}{3(1-v)}
$$

and $\lambda$ is Lamé's drained modulus. Expanding from this, Hsieh et al. [1987 1988] pushed the field towards analysis and quantification that focused more on the time lag between periodic location of the colloquially known Earth tidal bulge (position of predicted tide response) and the observed groundwater head changes (phase shift between predicted and observed tidal response) Gibson, 1963. The Hsieh et al. papers also addressed criticism raised by Narasimhan et al. [1984] of the 1967 Bredehoeft [1967] paper, concluding that although grain compressibility should be incorporated into Bredehoeft [1967], the method remains sound. Additionally, [Rojstaczer 1988a b] highlighted the potential for errors or noise to be introduced in the estimation if the effects of barometric changes were not properly corrected for and removed from the groundwater pressure response. The authors also pointed out the need to account for parameters further affecting the pressure response such as the well radius, lateral hydraulic diffusivity $(\langle K\rangle / S)$ of the aquifer, thickness and vertical pneumatic diffusivity and vertical hydraulic diffusivity of the saturated zone overlying the aquifer.

The next large step in development was a consolidation of theory by a United States Geological Survey (USGC) report by Merritt [2004], which reviewed the most popular literature methodologies for ET, ocean tides and BL to estimate aquifer properties. A selection of these methods was also tested as part of the review for their applicability of use in a southern Florida (USA) site. Textbooks such as Wang [2001]'s 'Theory of Linear Poroelasticity with applications to Geomechanics and Hydrogeology' and Agnew [2010]'s fundamentals of 'Earth Tides' have also helped establish the knowledge of the phenomenon.

Another review similar in approach to Merritt [2004], in terms of both reviewing and testing literature methodologies, by Cutillo and Bredehoeft [2011] reviewed the mathematics used within the literature focused on ET analysis. The review also established a new methodology 
that combines various aspects of previous works. In their review, Cutillo and Bredehoeft [2011] revisited Narasimhan et al. [1984]'s suggestions, confirming the diminished response that may be observed if an open bore hole is used for monitoring: the change in groundwater head due to the Earth tidal forcing will be diminished in its response by the concurrent barometric forcing pushing down on the exposed groundwater head in the well.

Burbey et al. [2012] took the method developed by Cutillo and Bredehoeft [2011] and supplemented the unknown variables through the use of non-tide-based methodologies, such as extensometers, to measure the tilt and strain (to determine Poisson's ratio) and BL combined with permeability values obtained from pump tests to estimate porosity. This treatment achieved a much improved estimation from the ET analysis, as it effectively removed the need to use literature values. However, studies such as this are relatively expensive and thus not effective for routine monitoring of systems over the necessary spatial and temporal scales required for adequate groundwater resource management [Harrington et al. 2011, Alley and Konikow, 2015].

Recent work by Xue et al. [2016] and Allègre et al. [2016] used ET to estimate vertical hydraulic diffusivity building upon the work by Hsieh et al. [1987]. Their method is based on the amplitude and phase shift response of the borehole water level fluctuations to Earth tide strains given by

$$
A_{i}=\left|\frac{h_{0}}{e_{0}^{t}}\right|=\frac{1}{S_{S}}\left[1-2 \exp \left(-\frac{z}{\delta}\right) \cos \left(-\frac{z}{\delta}\right)+\exp \left(-\frac{2 z}{\delta}\right)\right]^{\frac{1}{2}}
$$

and

$$
\Delta \phi_{i}=\left|\frac{h_{0}}{e_{0}^{t}}\right|=\tan ^{-1}\left[\frac{\exp \left(-\frac{z}{\delta}\right) \sin \left(\frac{z}{\delta}\right)}{1-\exp \left(-\frac{z}{\delta}\right) \cos \left(\frac{z}{\delta}\right)}\right],
$$

where subscript $i$ denotes an ET frequency component, $e^{t}$ is the tidal dilation strain and $h$ is the hydraulic head where the subscript 0 denotes the sequence term, $z$ is the depth below the surface, $\delta=\sqrt{\frac{2 \eta r}{\omega}}, \omega$ is the angular frequency of the tidal component, and $\eta_{r}$ is the hydraulic diffusivity, which equals the hydraulic conductivity $(\langle K\rangle)$ divided by the storativity $(S)$. This method then allows transmissivity and specific storage to be inferred using

$$
\eta_{r}=\frac{k}{\mu S_{s}}=\frac{\langle K\rangle}{\rho_{w} g S_{s}},
$$

where the permeability and transmissivity can then be related by

$$
k=\frac{\mu T}{\rho_{w} g b} .
$$

Here, $b$ is the thickness of the aquifer (or alternatively the saturated open or screened bore interval when the aquifer thickness is not accurately known [Allègre et al., 2016]), $\mu$ is the dynamic viscosity, $S_{s}$ is the specific storage, and $T$ is the transmissivity. Uncertainty can be calculated using co-variance matrices [Xue et al. 2016]. These papers are the first ET methodology to completely separate out the various ET signals to reduce the noise from other sources, in both the measured head responses and in the parameter estimation. In addition, Allègre et al. [2016] also verified their methodology by comparing results to values estimated from pump tests at the same site.

Allègre et al. [2016] found that they could accurately estimate the permeability by tidal analysis of passively monitored groundwater heads (no human induced forcing). The authors pointed out that the greatest limitation of their study was that the range of tidal response was 
near the detection limit of the equipment used combined with a $2.4^{\circ}$ uncertainty on the phase response. Finally Allègre et al. [2016] noted, "one should interpret specific storage results with caution since it is more likely to be sensitive to the amplitude accuracy of the measurements".

The papers of Bredehoeft [1967], Hsieh et al. [1987] and Cutillo and Bredehoeft [2011] now form the basis for several works expanding the method and our understanding of tidal analysis. Two such papers are Yu et al. [2017] and Vinogradov et al. [2018]. Yu et al. [2017] investigated the use of ET and found that it was unable to evaluate hydraulic conductivity in a finegrained low-permeability unit in comparison to hydraulic in situ testing. However, tidal analysis provided reasonable values for specific storage and effective porosity. Vinogradov et al. [2018] described the potential inaccuracies of the ET method caused by earthquakes and inflow variations. The authors found that the ground movements from seismic waves have a minimum influence on calculated phase shifts, whereas corrections for changes in flow due to both natural and anthropogenic effects are necessary.

\subsection{Groundwater response to barometric loading}

The effects of atmospheric pressure changes inducing a subsurface loading have been known for a long time to be a source of error in observed groundwater heads [Clark, 1967]. Subsurface stress originates from the loading and unloading of the Earth's crust in response to changes in atmospheric pressures within the atmosphere due to both gravitational and thermal processes [Siebert 1961, Chapman et al. 1969 Chapman and Malin, 1970 1 Palumbo 1998. Chapman and Lindzen, 2012]. Unlike ET, the main source of atmospheric pressure changes occur as the product of diurnal thermal expansion and cooling of the atmosphere, demonstrating that the AT oscillations are not gravitationally excited (Section 2.3 Ananthakrishnan et al. [1984]. It is noteworthy that much of the work regarding the effect of BL has been a byproduct of research on using ET and the need to correct for barometric effects [e.g., Clark 1967, Rojstaczer and Agnew, 1989].

Figure 9 demonstrates an counterintuitive, inverse relationship between atmospheric pressure and borehole levels (pressure heads) measured in boreholes, which is only observed in boreholes that are open to the atmosphere and requires explanation. Compared to a case of spatially limited loading such as the train example in Figure 8 , both the subsurface and the borehole water level are subject to barometric loading. In the subsurface, the stress is shared by the matrix and the fluid in proportions that correspond to their compressibility (see Table 3 [Domenico and Schwartz 1997]. While the formation will absorb some of the stress, the overall stress balance in the subsurface must remain the same. Thus, the pore pressure increase in the subsurface is less than the direct atmospheric pressure increase on the water column inside the borehole. The result is a pressure gradient and flow from the borehole into the aquifer, thereby lowering the water level in the borehole (see Figure 1 .

This inverse response is most pronounced when the aquifer matrix absorbs more stress (i.e., is least compressible), such as that of limestone or marble [Wang 2001]. It is important to note that this inverse response of the groundwater head to AT does not occur when the pore pressure is monitored with infrastructure that is sealed to the atmosphere, e.g., when using sealed piezometers or borehole packers. The difference is illustrated in Figure 10 [Cook et al., 2017].

Clark [1967] was the first to calculate the effective loading from changes in atmospheric pressure to remove its effects from other groundwater head fluctuations. [Clark 1967] defined 

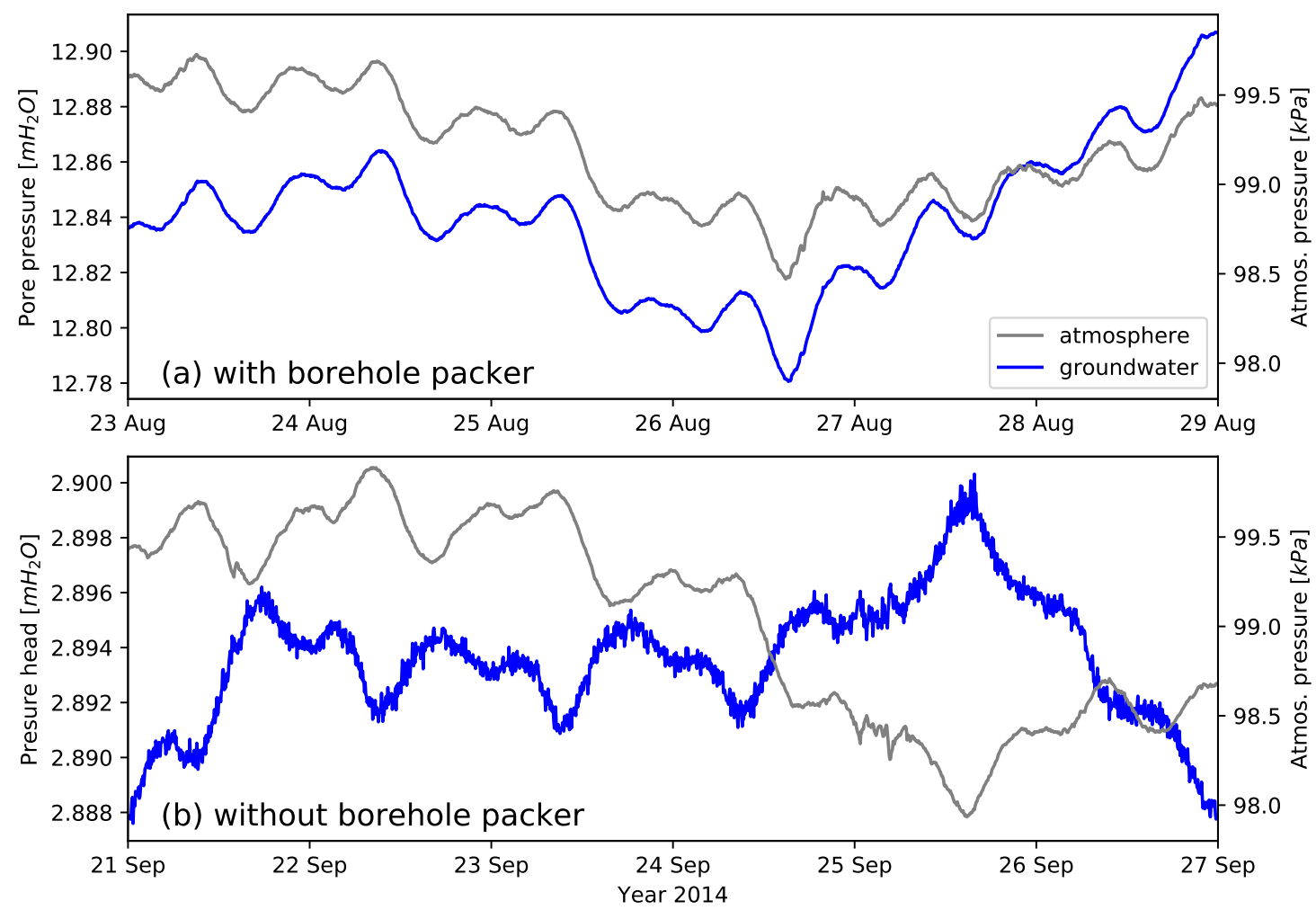

Figure 10: Example of the phase relationship between pore pressure, pressure head and atmospheric pressure during two passive investigation phases in a borehole (NMRDC1, data from Cook et al. [2017]): a) Pore pressure (hydraulic head) is in phase with the atmospheric pressure when the borehole is sealed from the atmosphere (here by temporary installation of a borehole packer); b) Pressure head is inverse to (out of phase with) the atmosphere when the borehole is open to the atmosphere.

the barometric efficiency as

$$
B E=\frac{\rho_{w} g \Delta h}{\Delta p}=-\frac{\rho_{w} g \Delta h_{p}}{\Delta p},
$$

where $\Delta h$ is a change in the hydraulic head $[m]$ and $\Delta p$ is the corresponding atmospheric pressure change $[\mathrm{Pa}]$. We note that the inverse response would result in a negative relationship with a change pressure head $\Delta h_{p}$ and have extended Equation 27 using a minus sign. Clark's method was further analyzed by Davis and Rasmussen [1993], who found it to be less biased than linear regression, where the estimate was found to be more consistent for both positive and negative atmospheric pressure changes, and thus for both linear and nonlinear trends, unlike linear regression [Clark 1967]. Davis and Rasmussen [1993] also suggested the implementation of a iterative recursive method to allow Clark's method to be used for shorter data records. 
$\mathrm{BL}$ has been considered a source of error or noise in observed groundwater heads for a long time. The primary purpose of calculating $B E$ was to allow for its removal to improve or enable other groundwater head-based investigations. For example, Rasmussen and Crawford [1997] removed barometric effects from drawdown due to pumping in order to increase the accuracy of the analysis. Spane [2002] removed $B E$ from water table levels to identify temporal changes in the flow direction of a flat-lying terrain. This $B E$ correction enabled prediction of contamination movements, which would otherwise not have been possible due to the minute differences in the piezometric surface over smaller distances.

There have been some early attempts to calculate aquifer properties from $B E$, such as that of Mehnert et al. [1999], who mathematically tied barometric fluctuations to borehole seismic events to calculate transmissivity, and Hobbs and Fourie [2000], who used the $B E$ calculations of Domenico and Schwartz 1997] to calculate the specific storage using an assumed porosity. However, the seminal work that can be seen as the modern use of $B E$ for calculating aquifer properties was by Gonthier [2003], who developed a graphical method to more accurately estimate the barometric efficiency. An example for this is shown in Figure 11p, which simply plots the groundwater time series against its corresponding atmospheric pressure time series and therefore allows estimation of a correlation. Here, the slope of the straight line is the negative $B E$. Due to its subjective nature, the graphical method has been seldom used compared to the Clark [1967] method. However, it is noteworthy that Gonthier [2003] mentioned the need to remove ET from the barometric signal and warned about the influence of ocean tide loading. This suggestion highlights the need for robust approaches to disentangle the impacts of EAT, a topic that will be discussed in Section 4.4 .

Timms and Acworth [2005] used groundwater head to estimate $B E$ and calculate the specific storage of clays. The authors further assessed the effects of the loading from rainfall (moisture loading) and the reduction of $\mathrm{BL}$ due to the passage of low-pressure storm cells. They highlighted the instantaneous effect of loading on pressure below and throughout the clay layers. In contrast, the phase lag between the surface response to the combination of rainfall and surface recharge and the recharge response at the base of the clay varied between 49 and 72 days. This phase lag was used to calculate the hydraulic conductivity $\langle K\rangle$ of a thick clay aquitard. Most notably, Timms and Acworth [2005] found that the in situ calculated specific storage values were 2 orders of magnitude less than those derived from lab testing using core samples from the same monitoring well. They hypothesized that this difference must be a result of the stress differing between field and laboratory conditions (i.e., cores not under in situ stress).

Acworth and Brain 2008] used frequency analysis to improve the reliability of poroelastic parameter estimates by removing ET from the observed well observations. Both Timms and Acworth [2005] and Acworth and Brain [2008] estimated BE using the approach by Gonthier [2003. and measured porosity independently with downhole sonic logging.

Smith et al. [2013] built on the work by Acworth and Brain [2008] using a much larger temporal data set and signal processing to remove ET effects. They noted that after correcting the groundwater heads, unfortunately, noise due to unknown sources was still present. However, they also proved that sealing the borehole off from the atmosphere, in this case by grouting the transducers in place, the dampening effect of the atmosphere pushing down into water within the borehole itself was removed, thus allowing a significantly improved measurement of the BL response. This method enabled estimates in very-low-permeability units such as aquitards.

Similarly, the advantages of sealing boreholes for improved BL measurements were also investigated by Price 2009] for vented and non-vented transducers and later by Cook et al. 

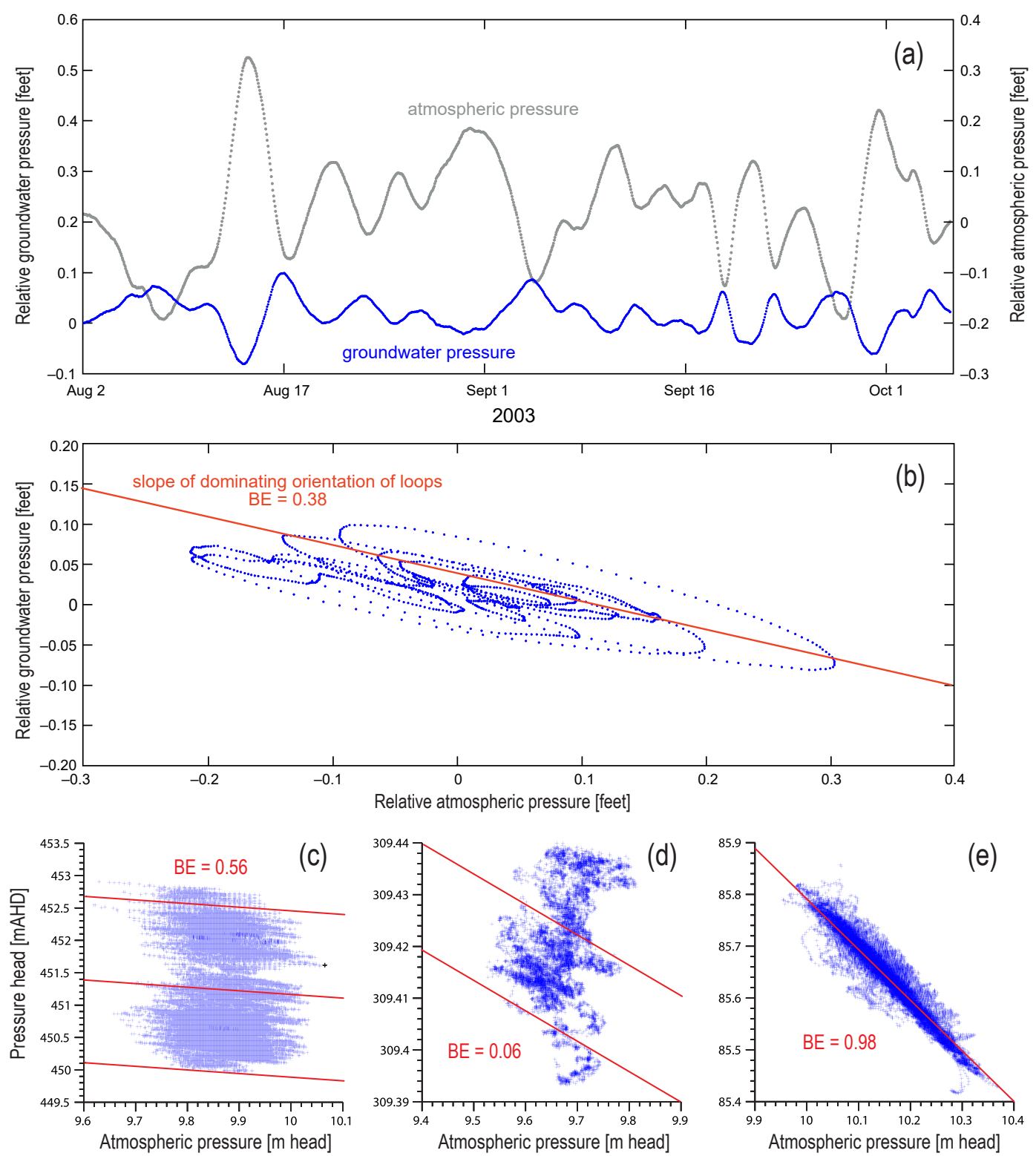

Figure 11: Illustration of the subjective graphical approach to estimate $B E$ by Gonthier 2003] (figure adapted): (a) atmospheric and pressure data and (b) a correlation in which the slope of the dominating orientation of loops determined by a regression (red line) represents $B E$. In comparison, the method by Acworth et al. [2016] (figure adapted) is objective (i.e., not based on graphical regressions) and removes the influences of Earth tides to reveal atmospheric impacts only. The results are illustrated for three aquifers in Australia (c: Baldry, d: Cattle Lane, e: Fowlers Gap) with differing values $0<B E<1$. 
[2017) using packers, with both authors obtaining conclusions similar to those of Smith et al. [2013]. Smith et al. [2013]'s work was also revisited and confirmed by Smerdon et al. [2014], replicating the methodology and conclusions at a different field site. They further found that specific storage was an order of magnitude less than previously published lab results for the studied areas [Price, 2009, Smith et al. 2013, Smerdon et al., 2014 Cook et al., 2017]. These results confirm the differences noted by Timms and Acworth [2005] and Acworth and Brain [2008] for other groundwater basins around the world [van der Kamp, 2001].

Lai et al. [2013] comprehensively evaluated the subsurface response to ET and BL in the frequency domain. To further improve the separation of $E T$ and $B L$ effects, they stacked borehole records, which reduced noise and error, thus enabling more sensitive analysis in areas with a low barometric efficiency. Progressing from this, Acworth et al. [2015a] performed a discrete Fourier transform (DFT) analysis, thus allowing for the use of sparser temporal data sets and superior isolation of particular harmonic components. Acworth et al. [2015a] also highlighted various effects that may have introduced noise. Potential errors include processes such as evapotranspiration altering the moisture within the subsurface diurnally with photosysthesis, causing moisture loading variations, as described in the review by van der Kamp and Schmidt [2017]. Other non-cyclical loading events such as snow melt or extreme rainfall events should be removed by the DFT and filtering [van der Kamp and Schmidt 2017]. For instance, Hendry et al. [2018] used a high-pass filter to isolate short-term changes by subtracting the long-term barometric trend. It is also at this point that the Acworth papers switched from using Gonthier [2003]'s graphic method for estimating barometric efficiencies to using the calculation method (according to Equation 27] from Clark [1967], due to the graphical procedure's limited effectiveness in low- $B E$ settings.

Acworth et al. [2016] developed a new frequency domain method that disentangles the impact of ET and AT on groundwater occurring at the same frequencies. This method requires using a synthetic ET record produced by TSoft [Van Camp and Vauterin 2005] and a spectral analysis to quantify amplitudes and phases of the ET and AT components of interest. The resulting equation is [Acworth et al., 2016]

$$
B E=\frac{S_{2}^{G W}+S_{2}^{E T} \cos (\Delta \phi) \frac{M_{2}^{G W}}{M_{2}^{E T}}}{S_{2}^{A T}},
$$

where $S_{2}^{G W}$ is the amplitude of the groundwater hydraulic head, $S_{2}^{E T}$ is the amplitude of the ET, $S_{2}^{A T}$ is the amplitude of the AT, $\Delta \phi$ is the phase difference between the Earth tide and atmospheric drivers, $M_{2}^{G W}$ is the amplitude of the groundwater hydraulic head caused by ET, and $M_{2}^{E T}$ is the amplitude of the ET. For the frequency values, please refer to Table 2. The method is generic and explained in more detail in Section 4.4. For the first time, this approach allows an objective quantification of $B E$, especially for conditions where $B E \rightarrow 0$. Figure 11 illustrates the superiority of this method compared to Gonthier [2003] and Clark [1967].

The method was then further distilled by Acworth et al. [2017], who presented a both theoretically and mathematically simplified version of the previous Acworth papers. The method also highlights how by using the well-established harmonic addition theorem [Havin and Jöricke, [1994] with measured atmospheric pressures, synthesized ET and the measured hydraulic heads, each signal can be separated out due to the harmonic tidal signal. Using the Acworth et al. [2017] method, the barometric efficiency can defined by Equation 27 from Clark [1967] and can 
then be related to the loading efficiency by [Jacob, 1940 van der Kamp and Gale 1983]

$$
B E+\gamma=1,
$$

where $\gamma$ is the loading efficiency. This can be expressed as a ratio of terms involved in aquifer compressibility [Domenico and Schwartz, 1997, Acworth et al., 2017]:

$$
\gamma=\frac{\beta}{\theta \beta_{f}+\beta} .
$$

where $\beta$ is the formation compressibility $\left(\mathrm{Pa}^{-1}\right)$ and $\beta_{f}$ is the fluid compressibility $\left(\mathrm{Pa}^{-1}\right)(4.59$. $10^{-10} \mathrm{~Pa}^{-1}$ at $20^{\circ} \mathrm{C}$ for water). By combining Equation 29 with Equation 30 and an alternative form of the equation for specific storage,

$$
S_{s}=\rho g\left(\beta+\theta \beta_{f}\right) .
$$

An equation that express the specific storage as a function of the barometric efficiency can then be derived:

$$
S_{s}=\rho g \beta_{f} \frac{\theta}{B E}=4.5 \times 10^{-6} \frac{\theta}{B E},
$$

David et al. 2017] showed for the first time that specific storage can change over time. Specific storage values derived from both BL and ET were used to quantify the extent of ground movement in several different strata above an underground long-wall coal mine. Although improved methods are now available for such analyses, this study highlighted that groundwater responses to EAT can be used to track changes in subsurface properties over time due to human-induced processes (e.g., extraction or injection in the subsurface).

A common disadvantage of methods using $B E$ to quantify compressible groundwater storage is that a porosity value must be assumed or measured. The most common source of porosity estimates currently come from either downhole geophysics such as sonic logs or laboratory testing on sediment cores. In both of these cases, heterogeneously derived secondary porosity, such as fracture, may be not included in these estimates.

Rau et al. [2018] combined cross-hole seismic measurements, objective $B E$ calculations and literature-based values for grain compressibility to constrain the poroelastic parameter space in the subsurface. The authors calculated depth profiles of specific storage using

$$
S_{s}=\rho_{w} g \frac{\alpha}{K_{v}^{u} \gamma(1-\alpha \gamma)},
$$

where $K_{v}^{u}$ is the undrained vertical bulk modulus. Their approach further allowed in situ quantification of all other elastic coefficients along a detailed depth profile. By combining their findings with physical properties previously derived from a sediment core [Acworth et al. 2015b], they noted that all of the subsurface water responds to stress. Importantly, they found that specific storage derived using EAT represents the total water content but that extractable storage can be significantly smaller due to an increasing fraction of adsorbed water when the grain size decreases. [Rau et al., 2018] determined a general upper limit for extractable specific storage as $1.3 \cdot 10^{-5} / \mathrm{m}$, with implications for hydrogeology and groundwater resource estimation.

The above discussion highlights that significant effort has been devoted to investigating the groundwater impact to EAT and using this to quantify subsurface properties. However, this discussion also demonstrates that the use of spectral analysis is an underutilized tool that 

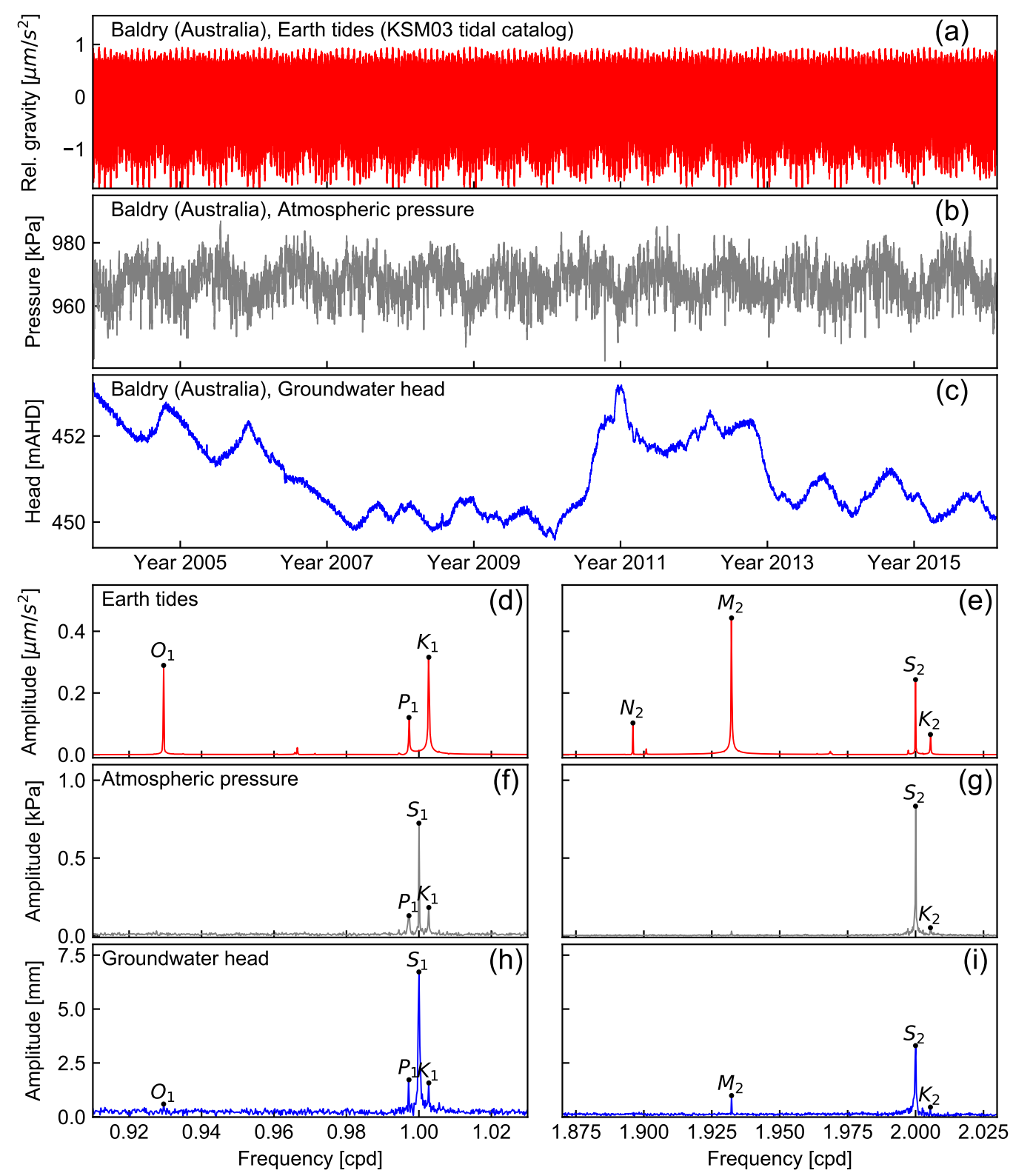

Figure 12: Time series and amplitude spectra of a 4,497-day continuous record at Baldry (Australia): (a,d,e) tide-generating potential synthesized using PyGTide [Rau 2018], (b,f,g) atmospheric pressure measurement (same example as used in Figure 6), and (c,h,i) groundwater head measurement. Note that the atmospheric and groundwater data are the same as were used in Acworth et al. [2016]. 
promises further potential. Figure 12 shows an example of a 12-year continuous record and amplitude spectra of the atmospheric pressure, groundwater head and calculated ET. The groundwater responses to different ET and AT components are clearly identified. However, the fact that the groundwater response magnitude is inconsistent for different frequency components (compare $O_{1}, P_{1}$ and $K_{1}$ ) demonstrates that further research is required to elucidate the role of the porous and elastic subsurface as a frequency filter for stress induced from EAT.

\subsection{Disentangling the impacts of Earth and atmospheric tides}

The poroelastic theory summarized in Section 3 contains a large number of variables, and the parameter space is therefore difficult to constrain in field investigations. Bredehoeft [1967] noted that more subsurface properties could be obtained when ET analysis is combined with $\mathrm{BL}$ estimates. The value of using such a combined approach has been proposed multiple times during the development and application of ET methods [e.g., Narasimhan et al., 1984 Rojstaczer and Agnew 1989, Ritzi et al. 1991]. For example, Cutillo and Bredehoeft [2011] and Burbey et al. [2012] successfully combined ET analysis with barometric efficiency estimations to arrive at a more complete quantification of subsurface hydrogeomechnical parameters, namely, permeability, porosity and specific storage.

These works generally separate $\mathrm{ET}$ and $\mathrm{BL}$ effects by using $B E$ derived from correlating barometric and groundwater pressure (Figure 11. This approach is subjective and has many disadvantages. For example, any processes contained in the groundwater heads that are not related to atmospheric forcing, such as groundwater recharge or discharge or surface loading from rainfall, will distort the correlation. Further, when the method is applied to subsurface systems with very low $B E$ values, meaningful correlations cannot be obtained. The use of AT to calculate $B E$ has frequently been dismissed as impossible [e.g., Cutillo and Bredehoeft 2011] because the frequencies of the atmospheric tidal components are very close to or overlap with those of ET, e.g., $S_{1}$ and $K_{1}$ or $S_{2}$ (Table 1 ).

Acworth et al. [2016] provided a breakthrough in understanding while developing a new method to quantify $B E$ from the groundwater response to AT only by removing the ET effect. To isolate the groundwater amplitude fraction that is caused solely by AT, the harmonic addition theorem (HAT) can be invoked. If two harmonic drivers acting at the same frequency are combined, such as the groundwater response to the $S_{2}$ component in both ET and AT, the response is a new harmonic with the same frequency but different amplitude and phase. This effect is graphically explained in Figure 13

Note here that according to $B E$ being negative, there is a phase difference of $\pi$ (or $180^{\circ}$ ) between the AT and the groundwater response for confined conditions. That is, when the atmospheric pressure is at its maximum, the groundwater pressure must be at a minimum. This phase reversal is only seen for the groundwater head in an atmospherically open borehole, not in the aquifer, and is caused by the atmospheric stress acting on the groundwater head in the borehole in relation to that acting on the aquifer, where the matrix carries some of the stress. The general phase difference between the ET and its groundwater response can vary according to the borehole geometry and subsurface properties [e.g., Bredehoeft, 1967 Narasimhan et al. 1984, Hsieh et al., 1987].

The amplitude of the response, as seen in the amplitude spectrum of groundwater heads, depends on the phase difference between both drivers. If no phase difference exists $(\Delta \phi=0)$, then the amplitude response is simply added (Figure 13a); analogously, the amplitude is sub- 


$$
\begin{aligned}
& \text { Earth tide }(\mathrm{ET})+\text { Atmospheric tide }(\mathrm{AT}) \quad=\quad \text { Groundwater response }(\mathrm{GW}) \\
& A_{E T} \cdot \sin \left(\phi_{E T}\right)+A_{A T} \cdot \sin \left(\phi_{A T}\right) \quad=\quad A_{G W} \cdot \sin \left(\phi_{G W}\right)
\end{aligned}
$$
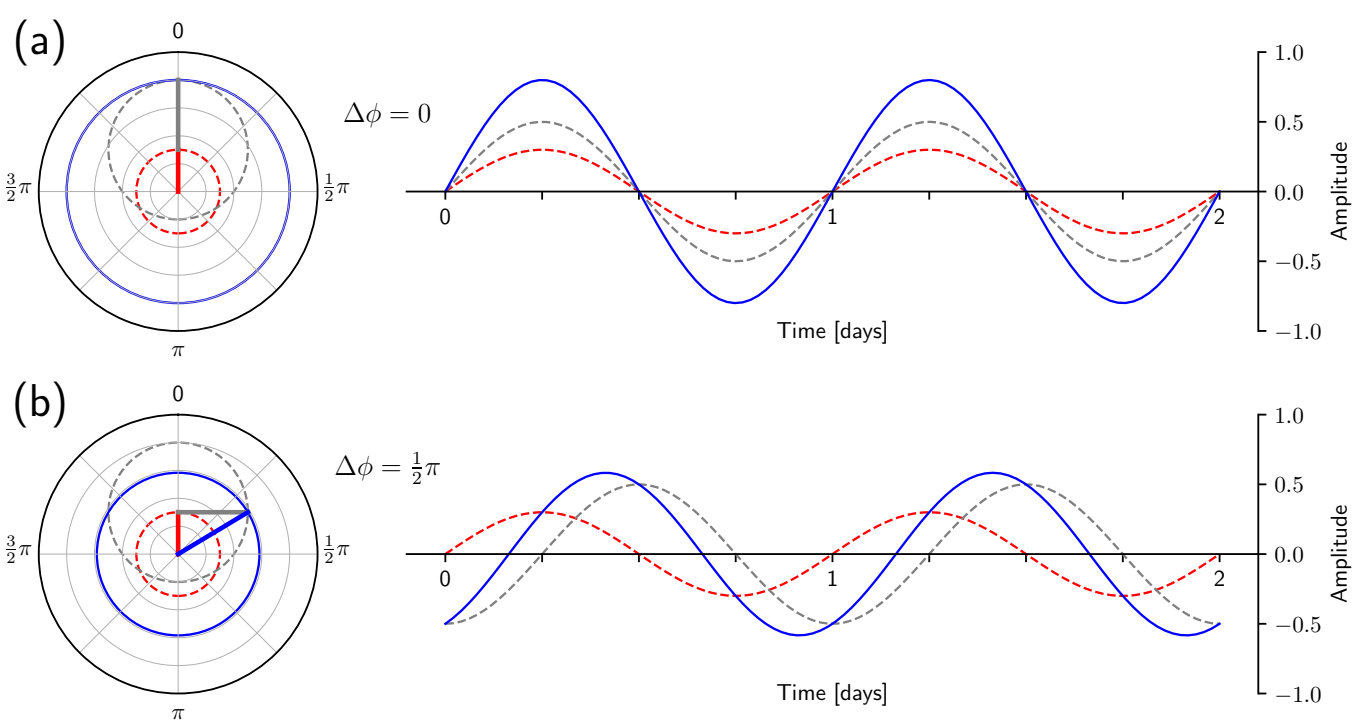

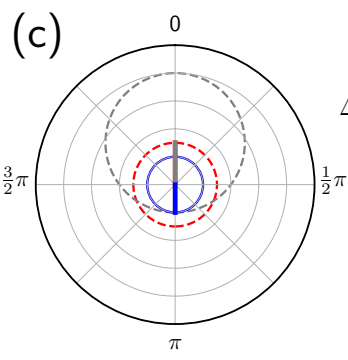

Complex domain

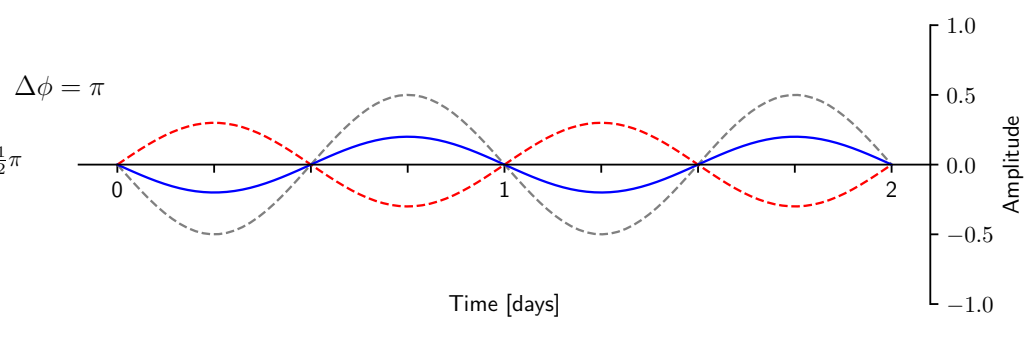

Time domain

Figure 13: Conceptual overview of the groundwater response to components of the Earth and atmospheric tide with the same frequency, such as $S_{2}$ (Table 1), but different amplitudes and phases. The amplitude and phase of the individual contributions can be disentangled using the harmonic addition theorem [Havin and Jöricke 1994]. Note that this conceptual explanation assumes that the groundwater reacts instantaneously to changes in the driver signal, i.e., it does not consider the phase difference of $\pi$ between atmospheric tides and its groundwater response.

tracted at a phase shift of $\Delta \phi=\pi$ (Figure 13;). The amplitude for arbitrary phase shifts (Figure 13p) can be determined using HAT, but both the amplitudes and phases of the drivers must be known [Havin and Jöricke, 1994]. These features can be obtained by spectral analysis, i.e., transforming time series data into the frequency domain using the DFT. 
Acworth et al. [2016] applied spectral analysis to investigate the frequency content contained in atmospheric and groundwater pressures, for example as seen in Figure 12 They observed that there are frequencies at which the groundwater responds to ET only, such as $M_{2}$. The relative contribution of gravitational tides can therefore be quantified by using a synthetic ET record for that location. Since this relative ET contribution must be the same at a close-by frequency that is also affected by AT $\left(S_{2}\right)$, the magnitude can be determined by cross-reference to the amplitude at that frequency using the synthetic ET spectrum. Consequently, HAT enables the determination of the groundwater response for which only the AT is responsible.

This approach is objective, overcomes previous limitations and allows a direct calculation of $B E$ using AT. Furthermore, the underlying principle behind this technique enables generic quantitative separation of the EAT contributions embedded in groundwater heads. This consideration provides new opportunities for revisiting previous theory in order to develop new methods that result in increased accuracy when parameters are quantified using both ET and AT.

\subsection{Groundwater confinement and response to tides}

In hydrogeology, knowledge of confinement is crucial for groundwater system modeling, as the mathematical equations used to describe the physical reality are different [Domenico and Schwartz 1997 Fetter 2000]. To determine whether a subsurface geological unit is confined, the location of the groundwater pressure head is related to the lower boundary of a confining geological unit. Confined conditions are defined by a pressure head that is higher than the lower boundary of a capping low permeable geological unit (aquiclude or aquitard), whereas it is lower for unconfined conditions and forms the upper boundary of such an aquifer [e.g., Domenico and Schwartz 1997]. Confinement is traditionally determined by observing the rise of the water table during drilling, inferring it from lithology or evaluating the response of the hydraulic head to pumping [Rahi and Halihan 2013]. Further, it is generally assumed that the formation is rigid, and the overall compressibility required to describe confined conditions is lumped into the specific storage parameter.

From a poroelastic perspective, water displacement in response to stress is different for confined or unconfined groundwater conditions [Wang, 2001]. A normal stress applied to a saturated porous material will pressurize the fluid occupying the pores unless the water can be displaced or the pressure rapidly dispersed. The groundwater head in a confined state is hydrostatic and spreads induced strain throughout a formation until equilibrium is reached or until it is relieved by water displacement, drainage, deformation or a general reduction in the initial induced stress [Galvin 2016].

The impact of EAT differs for confined and unconfined conditions Bredehoeft, 1967 Acworth et al. 2015a 2016]. Where the aquifer is confined, the increase and decrease in strain on the Earth's crust will be accommodated by both the matrix and pore fluid [Hsieh et al., 1987 Wang, 2001], as demonstrated in Section 3 For example, Bredehoeft [1967] noted that the presence of ET components in groundwater heads indicates confined conditions. Acworth and Brain [2008] found that $B E \approx 0$ indicates unconfined conditions in fractured rock, whereas $B E>0$ illustrates confined conditions. Butler et al. [2011] investigated the aquifer response to $\mathrm{BL}$ and noted that the degree of confinement can be determined under semiconfined conditions, represented by $B E$ values between 0 (unconfined) and 1 (confined).

As mentioned in the section above, it has long been known that some ET components have the same frequency as AT, for example, $S_{2}$, and that the result is a harmonic superposition 


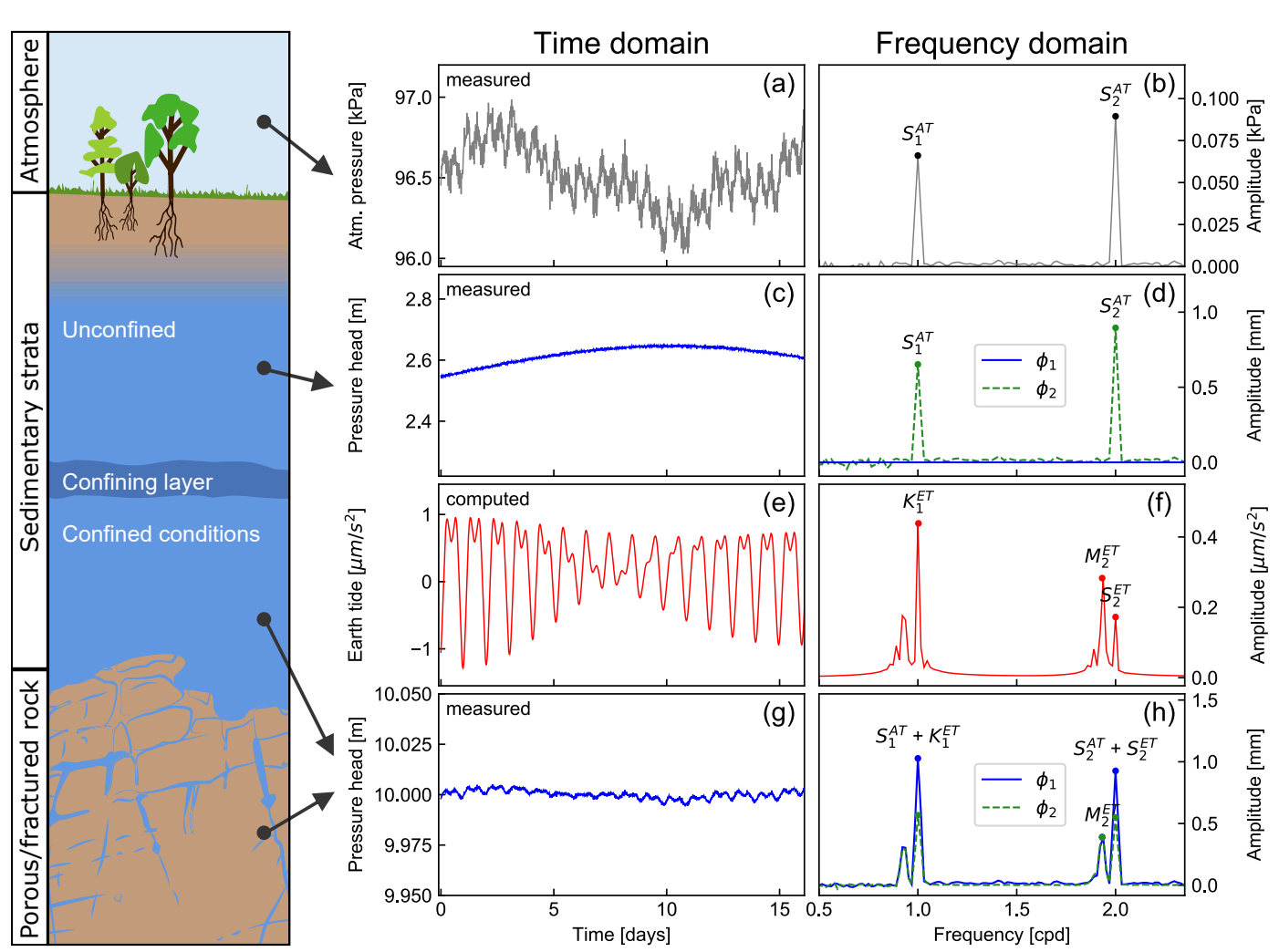

of both components. Depending on the phases of both signals, this relation can lead to an increase or a decrease in the tidal response compared to other components (compare $\phi_{1}$ and $\phi_{2}$ in Figure 14 h and see Figure 13 for an explanation). Consequently, the ET components should be used in isolation from the atmospheric signal to improve the interpretation of the degree of confinement. Figure 14 summarizes the effect of tides on confined and unconfined conditions.

Figure 14: Conceptual overview of the influence of tidal forces down through a subsurface profile. (a) Measured atmospheric pressure time series, (b) amplitude spectrum of (a) showing atmospheric tide components, (c) unconfined pressure head time series, (d) amplitude spectrum of (c) for unconfined conditions $\left(\phi_{1}\right.$ represents an unconfined groundwater response, whereas $\phi_{2}$ illustrates a delay in atmospheric pressure propagation through the vadose zone), (e) computed relative gravity due to Earth tides (calculated using PyGTide [Rau, 2018]), (f) amplitude spectrum of signal in (e) showing the Earth tide components, (g) measured confined pressure head time series, and (h) amplitude spectrum of the confined pressure head ( $\phi_{1}$ and $\phi_{2}$ refer to different responses caused by a harmonic addition of Earth and atmospheric tides acting at the same frequencies).

In the case of AT, the stress is assumed to be of infinite extent laterally, does not introduce any horizontal pressure gradients and therefore does not cause horizontal water displacement [Cutillo and Bredehoeft, 2011]. Weeks [1978] and Weeks [1979] utilized BE to reflect the state of confinement of an aquifer; when confined, barometrically induced groundwater head 
fluctuations are theoretically in phase with barometric changes within a formation and are always a constant fraction of the barometric fluctuations. However, when the confinement is assessed using a borehole open to the atmosphere, the groundwater head fluctuation is out of phase with the atmospheric pressure change (see Figure 1 and the explanation in Section 4.4. Rasmussen and Crawford [1997] further noted that in a confined aquifer, the groundwater head response to $\mathrm{BL}$ is instantaneous, whereas in unconfined aquifers, this response is not evident due to the instantaneous equilibration of the atmospheric pressure change through the pore space of the unsaturated zone. Lai et al. [2013] found that wells resulting in a $B E>1$ can be assumed to reflect unconfined conditions.

Acworth et al. 2016] noted that an instantaneous reaction presumes that a phase difference of $\pi$ (or $180^{\circ}$ ) must exist between atmospheric pressure fluctuations induced by tides and its groundwater head response in an atmospherically open borehole if a groundwater system is confined. The effect was exploited to determine the degree of confinement using groundwater heads from a series of piezometers arranged vertically through a vertical sequence of smectite clays (Acworth et al. 2017]. Their results also illustrated a change in phase difference over time, which was related to a change in system confinement in response to groundwater head changes due to periods of dry and wet conditions at the ground surface. Specifically, during wet periods, increased saturation of clay layers near the surface altered the degree of confinement (i.e., reducing the direct connection between atmosphere and unsaturated zone and thus the instantaneous pressure equilibration at the water table).

The presence, absence or relative magnitude of the principal tidal components has also been proven useful as a method for determining an aquifer's state of confinement beyond confined or unconfined. Rahi and Halihan [2013] demonstrated that where the $S_{2}$ signal is dominating but the $M_{2}$ tidal signal is still present, the aquifer can be classified as semiconfined. Where $M_{2}$ is dominating, the aquifer is confined, and where $M_{2}$ is not present, the aquifer is unconfined [Bredehoeft, 1967, Rahi and Halihan 2013].

Whereas a lack of ET components in groundwater heads can indicate unconfined conditions, this relationship is more complicated for AT. In perfectly unconfined systems, the pressure variations induced by AT propagate instantaneously through the unsaturated zone, do not induce stress, and therefore do not impact groundwater heads. However, unconfined systems are often overlain by a variably saturated unit containing partially trapped and highly compressible air or zones of lower permeability, where pressure propagation can be delayed. Such phenomena have been reported in laboratory experiments [Norum and Luthin 1968] and field settings Weeks, 1979]. Although this effect prevents the use of AT to detect unconfined conditions (compare $\phi_{1}$ and $\phi_{2}$ in Figure 14d), AT can be exploited to characterize the unsaturated zone. In fact, the delay between atmospheric pressure changes and groundwater response has been used to develop barometric response functions to infer stratigraphic details [Butler et al. 2011] or unsaturated zone properties [e.g., Hussein et al., 2013, Odling et al., 2015].

The concepts of confined and unconfined groundwater conditions should be thought of as ideal end-members. It is important to note that real subsurface systems have a degree of confinement that lies somewhere in between. In fact, Briciu [2015] noted a periodic change in the discharge of many inland rivers, which is caused by groundwater contribution to river flow from tidal stress. This tidal response in groundwater discharge is evidence for the semiconfined nature of many aquifers adjacent to streams.

Our discussion illustrates that the assumption of either strictly confined or unconfined conditions is simplistic. For example, confinement is often assumed to be static, i.e., remain con- 
stant over time, despite the fact that groundwater heads can change over time. We propose that the use of tides to determine the degree of groundwater confinement from pressure measurements alone should be further developed. Changes in groundwater response to EAT could indicate changes in hydrogeological conditions, e.g., confinement or increasing land subsidence.

\section{Conclusions and future potential}

In this review, we comprehensively survey and combine knowledge from the literature in geophysics and geodesy (related to ET in Section 2.2), atmospheric science (related to AT in Section 2.3), geomechanics (related to the theory of subsurface poroelasticity in Section 3 ) and hydrogeology (related to tidal impacts on groundwater and methods exploiting tides in Section 4). In doing so, we connect research from multiple disciplines to arrive at a new understanding of how the impact of EAT can be used to characterize groundwater systems and quantify subsurface hydrogeomechanical properties. For example, we illustrate that EAT are ubiquitous, that they cause detectable subsurface deformations due to the poroelastic properties of the lithology, and that these deformations manifest as fluctuations in the groundwater head. Tides present a naturally occurring signal embedded in pressure measurements and can therefore be used as a natural hydraulic stressor to reveal information about the subsurface.

Our synthesis reveals that exploiting the groundwater response to EAT impacts requires simultaneous records of three parameters:

1. Earth tides (ET): Gravity fluctuations caused by the movement of celestial bodies relative to Earth cause ET, which are reflected in subsurface deformations and pressure changes. Gravity measurements are not required because gravitational tides can be synthesized accurately using precisely known astronomical relationships and correlate well with observations of body tides and ground surface movement. The ET can be produced for known geocoordinates (latitude, longitude and elevation) and a time period of interest using TSoft [Van Camp and Vauterin 2005], ETERNA PREDICT [Wenzel, 1996] or PyGTide [Rau, 2018.

2. Atmospheric tides (AT): Atmospheric tides occur over large global regions with amplitudes that are strongest at the equator and diminish towards the poles. AT are embedded in the atmospheric pressure, which is a parameter routinely measured by weather stations. Such records should be available at high frequency and with spatial coverage for most locations around the globe. In fact, groundwater investigations generally include atmospheric pressure measurements for the barometric correction of pressure recordings from non-vented pressure transducers.

3. Groundwater heads (GW): Pressure transducers with automated loggers are increasingly deployed in monitoring bores and piezometers to track groundwater heads at daily or subdaily frequencies. Fortunately, monitoring bores and piezometers are far more prevalent than bores that are suitable for aquifer pumping tests and also provide data from strata with limited groundwater yield. Many water management jurisdictions have been operating such groundwater monitoring programs for at least a few decades, and data from some key bore sites are made available on the web in real time. Consequently, groundwater head time series should be available with appropriate temporal resolution ( $\geq 8$ samples per day) and duration ( $\geq 1$ month) at a large number of locations around the world. Using appropriate equipment, such records should also have an appropriate pressure resolution ( $<1 \mathrm{~mm}$ head), 
Combining these components with existing poroelastic theory (Section 3 allows the determination of groundwater confinement and quantification of subsurface hydrogeomechanical properties, namely, permeability or transmissivity, specific storage, porosity and formation compressibility. Figure 15 summarizes this finding. We propose the term tidal subsurface analysis (TSA) to describe this emerging methodological approach.

Our review also reveals many open questions that require further research:

- It is evident that the subsurface acts as a tidal frequency filter, i.e., processes and properties of the ground between the surface and the point of monitoring modify amplitudes and phases in the groundwater head. Knowledge is limited about how the hydrogeomechanical properties influence this filter and how to effectively exploit this for subsurface characterization.

- There is currently uncertainty regarding the representative scale of hydrogeomechanical properties derived from passive techniques at low stress. The zones of influence near the bore screen and between the ground surface and the point of monitoring are poorly constrained.

- Tides are harmonic functions characterized by two parameters, amplitude and phase. They simultaneously act as stressors on the subsurface. While the contributions of EAT on the groundwater response can now be disentangled [Acworth et al., 2016], the influence of subsurface properties on the tidal transfer functions should be systematically explored, i.e., how to quantitatively explore the relationship between the amplitude and phase of the stressors and the resulting groundwater head response.

- Within confined aquifers, a direct ET response can be observed, while the AT response is out-of-phase. It may be possible to determine a characteristic signature to reliably identify semiconfined or unconfined groundwater conditions. Development of a quantitative measure for the degree of confinement could enable comparison between aquifers and over time and could help assess subsurface extraction or injection projects.

- Few studies have compared hydrogeomechanical parameters obtained from TSA with those from traditional investigation techniques. Further research is required to benchmark results and increase confidence in the accuracy and reliability of TSA for a variety of subsurface conditions.

- Combining TSA with traditional hydraulic investigation techniques would constrain the poroelastic and hydraulic parameter space for numerical models. For example, this approach could help to determine both hydraulic transmissivity and storativity from the hydraulic diffusivity and therefore reduce the large uncertainty inherent in aquifer pumping test analyses.

- Specific storage from TSA and associated site data is critical to constrain complex coupled groundwater-surface water models that evaluate the effects of groundwater head drawdown on rivers, reservoirs, springs and wetlands.

- Numerical groundwater models must consider physically plausible ranges of specific storage (i.e., according to poroelastic theory and TSA) and consider variations of specific storage during sensitivity and uncertainty analyses. It is essential to consider heterogeneity of these parameters and aquifer boundary conditions, and it is particularly important to evaluate poroelastic effects on pore pressure and storage in groundwater or geomechnical models of subsurface responses to extraction or construction activities. 
Addressing these research gaps will deliver more confidence in the results of TSA and enable mature TSA approaches to become a new standard in the toolboxes of several disciplines, including hydrogeology and geomechanical engineering.

TSA is a passive technique, as it uses naturally occurring astronomical and atmospheric forcing. It does not require active hydraulic stressing and therefore is far less expensive and resource-intensive than traditional methods, such as hydraulic aquifer testing, which requires significant equipment, power supplies and personnel for several days at each site. Ideally, this method can be used to complement or, if further developed, altogether replace hydrogeological and hydrogeophysical investigation techniques relying on active forcing. Further, TSA could be automated and applied to decades of existing groundwater and atmospheric pressure data contained in global monitoring archives.

TSA reveals the average subsurface processes and properties over the time window of the data that are used. It could therefore also be applied in time-steps to produce time series that reveal temporal changes of groundwater processes and properties (in comparison, pump tests are only done at one point in time). Consequently, TSA offers an unprecedented opportunity for gaining insight into subsurface processes and properties over both space and time. In addition, TSA should become a routine approach that can add enormous value to existing monitoring programs. For example, for the first time, this could support time-adaptive decisionmaking in subsurface resource management. Such advantages exceed our current capabilities and represent a paradigm shift for investigating and managing groundwater and subsurface resources globally. 


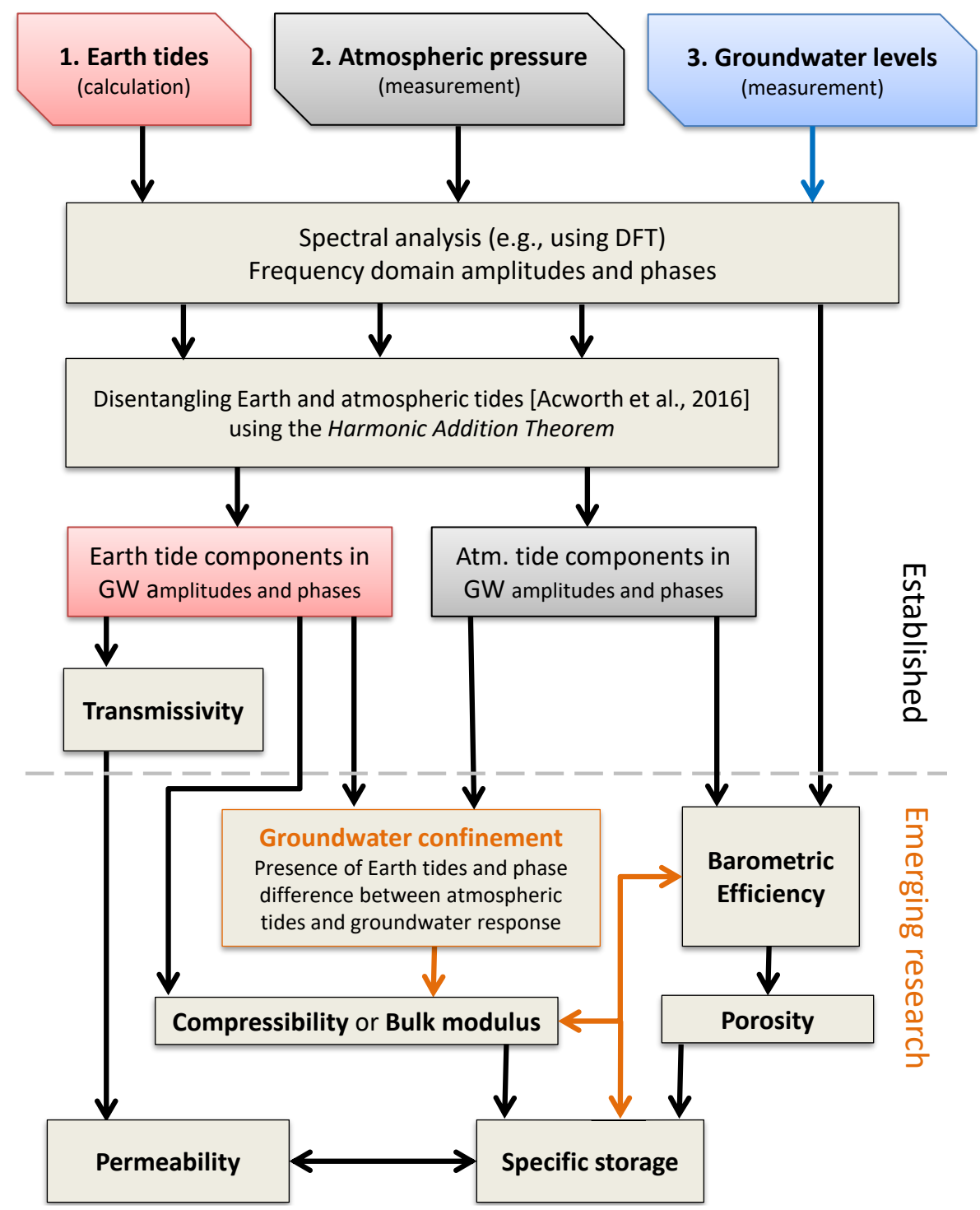

Figure 15: Overview of the suggested workflow for quantifying subsurface properties using the groundwater response to EAT. Previous research inferred confinement [Bredehoeft, 1967 Acworth and Brain 2008 Rahi and Halihan, 2013: Lai et al. 2013: Acworth et al. 2016, 2017], transmissivity [Cutillo and Bredehoeft, 2011], permeability [Allègre et al., 2016], permeability [Cutillo and Bredehoeft, 2011] Allègre et al. 2016], specific storage [Lai et al., 2013: Acworth et al. 2016: Allègre et al., 2016], porosity [Cutillo and Bredehoeft 2011; Lai et al. 2013] and compressibility (or bulk modulus) [Lai et al., 2013; Acworth et al. 2016, 2017]. The new ability to disentangle ET and AT necessitates further research to streamline the theory and enable objective quantification of hydrogeomechanical properties. 
Table A.1: Nomenclature

\begin{tabular}{|c|c|}
\hline Symbol & Definition and SI Units \\
\hline \multicolumn{2}{|c|}{ General Variables } \\
\hline$b$ & Thickness of the aquifer $[\mathrm{m}]$ \\
\hline$g$ & Gravity $\left[9.81 \mathrm{~m} / \mathrm{s}^{2}\right]$ \\
\hline$\rho$ & Bulk density $\left[\mathrm{kg} \cdot \mathrm{m}^{-3}\right]$ \\
\hline$\rho_{w}$ & Density of water $\approx 998\left[\mathrm{~kg} \cdot \mathrm{m}^{-3}\right]$ \\
\hline$t$ & Time $[s]$ \\
\hline$z$ & Depth $[m]$ \\
\hline$r$ & Average radius of the Earth $[\mathrm{m}]$ \\
\hline$i$ or $j$ & Index $[-]$ \\
\hline \multicolumn{2}{|c|}{ Poroelastic Variables } \\
\hline$E$ & Young's modulus [GPa] \\
\hline$v$ & Poisson's ratio [-]; in some other texts denoted as $\mu$ \\
\hline$v_{u}$ & Undrained Poisson's ratio $[-]$ \\
\hline$G$ & Shear modulus $[G P a]$; in some other texts denoted as $\mu$ \\
\hline$K$ & Bulk modulus $[G P a]$ \\
\hline$K_{s}^{\prime}$ & Unjacketed bulk modulus $[G P a]$ \\
\hline$K_{s}$ & Solid grain modulus $[G P a]$ \\
\hline$K_{\theta}$ & Unjacketed pore incompressibility $[G P a]$ \\
\hline$K_{w}$ & Bulk modulus of water $[G P a]$ \\
\hline$K_{u}$ & Undrained bulk modulus $[G P a]$ \\
\hline$K_{v}$ & Vertical bulk modulus $[G P a]$ \\
\hline$\beta$ & Bulk compressibility of the medium $[G P a]$ (equal to $1 / K$ ) \\
\hline$\beta_{s}$ & Grain compressibility $[G P a]$ \\
\hline$\beta_{f}$ & Compressibility of fluid $[\mathrm{GPa}]$ \\
\hline$\beta_{w}$ & Compressibility of water $[\mathrm{GPa}]$ \\
\hline$\sigma$ & Mean stress $[-]$ \\
\hline$e$ & Dilation $[-]$ \\
\hline$e^{t}$ & Tidal dilation strain $[-]$ \\
\hline$\zeta$ & Mass increment $[\mathrm{kg}]$ \\
\hline$\lambda$ & Lamé's drained modulus (defined in equation 22 \\
\hline$B E$ & Barometric efficiency [-] (defined in equation 27 \\
\hline$\gamma$ & Loading efficiency $[-]$ (defined in equation 29 \\
\hline$V_{p}$ & P-wave (Pressure wave) velocity $[\mathrm{m} / \mathrm{s}]$ \\
\hline$V_{s}$ & S-wave (Shear wave) velocity $[\mathrm{m} / \mathrm{s}]$ \\
\hline$\underline{\bar{q}}$ & Flow vector $[\mathrm{m} / \mathrm{s}]$ \\
\hline$\overline{\bar{\sigma}}$ & Stress tensor, with entries as $\sigma_{i j}$ \\
\hline$\overline{\bar{\epsilon}}$ & Strain tensor, with entries $\epsilon_{i j}$ \\
\hline$p$ & Pore pressure scalar \\
\hline$\xi$ & Increment of fluid content scalar \\
\hline
\end{tabular}


${ }_{S}^{L} h \quad$ Love-Shida number; measurement of the vertical (radial) displacement of the Earth's elastic properties [-]

${ }_{S}^{L} k \quad$ Love-Shida number; ratio of the additional potential due to the deformation [-]

${ }_{S}^{L} l \quad$ Love-Shida number; ratio of the horizontal (transverse) displacement of an element of crustal mass to that of the corresponding static ocean tide [-]

$\alpha \quad$ Biot-Willis coefficient [-] (Equation 7

$B \quad$ Skempton's coefficient [-] (Equation 8

$R \quad$ Biot modulus, reciprocal of constant stress storage coefficient [-]

$H \quad$ Reciprocal of the poroelastic expansion coefficient [-]

Hydrogeological Variables

$Q \quad$ Fluid source or sink; flow velocity $\left[\mathrm{m}^{3} / \mathrm{s}\right]$

$\theta \quad$ Total porosity (water content in saturated zone) [-]

$\eta_{r} \quad$ Hydraulic diffusivity $\left[\mathrm{m}^{2} / \mathrm{s}\right]$

$k \quad$ Intrinsic permeability $\left[\mathrm{m}^{2}\right]$

$\mu \quad$ Dynamic viscosity for water $[\mathrm{Pa} \cdot s]$

$S \quad$ Storativity [-]

$S_{S} \quad$ Specific storage $\left[\mathrm{m}^{-1}\right]$

$S_{s}^{v} \quad$ Uniaxial specific storage $\left[\mathrm{ms}^{2} / \mathrm{kg}\right]$

$T \quad$ Transmissivity $\left[\mathrm{m}^{2} / \mathrm{s}\right]$

$P \quad$ Pressure $[\mathrm{Pa}]$

$\langle K\rangle \quad$ Hydraulic conductivity $[\mathrm{m} / \mathrm{s}]$

$b \quad$ Aquifer thickness $[\mathrm{m}]$

$h \quad$ Hydraulic head $[\mathrm{m}]$

$\Delta h_{p} \quad$ Hydraulic head response $[\mathrm{m}]$

Signal Processing Variables

$w \quad$ Angular frequency of tidal component $[\mathrm{rad} / \mathrm{s}]$

A Amplitude response [-]

$\Delta \phi \quad$ Phase shift $[\mathrm{rad}]$

$V \quad$ Tidal potential $\left[\mathrm{m}^{2} / \mathrm{s}^{2}\right]$

Primary Tidal Components (see also Table 1 )

$S_{1} \quad$ Principal Solar tide at $1 \mathrm{cpd}$

$S_{2} \quad$ Principal Solar tide at $2 \mathrm{cpd}$

$S_{2}^{G W} \quad$ Amplitude of the hydraulic head at $2 \mathrm{cpd}$

$S_{2}^{E T} \quad$ Amplitude of Earth tide (ET) at $2 \mathrm{cpd}$

$S_{2}^{A T} \quad$ Amplitude of atmospheric tide (AT) at $2 \mathrm{cpd}$

$M_{2} \quad$ Principal Lunar tide at $1.9324 \mathrm{cpd}$

$M_{2}^{G W} \quad$ Amplitude of the hydraulic head of the Earth tides [ $\left.\mathrm{m}\right]$

$M_{2}^{E T} \quad$ Amplitude of the Earth tide $[\mathrm{m}]$

$K_{1} \quad$ Lunar-Solar tide at $1.0029 \mathrm{cpd}$

$O_{1} \quad$ Principal Lunar at $0.9295 \mathrm{cpd}$

$P_{1} \quad$ Diurnal Lunar perigee at $0.9973 \mathrm{cpd}$

$\mathrm{N}_{2} \quad$ Lunar elliptic at $1.8957 \mathrm{cpd}$ 


\section{Acronyms}

AT Atmospheric Tides

BE Barometric Efficiency

BL Barometric Loading

DFT Discrete Fourier Transform

ET Earth Tides

EAT Earth and Atmospheric Tides

FFT Fast Fourier Transform

GW Groundwater

HAT Harmonic Addition Theorem (see Havin and Jöricke [1994])

TSA Tidal Subsurface Analysis

TGP Tide Generating Potential

\section{Acknowledgments}

GCR conceived the idea for this work. The paper was drafted by TCM with contributions (section 3 and various subsections) and guidance from GCR, with additional revisions, supervision, edits and contributions by WAT and MSA throughout. The data that was used in this publication is available from the authors upon request. Some of the data used in this paper were collected with equipment provided by the Australian Federal Government financed National Collaborative Research Infrastructure Strategy (NCRIS). The groundwater data is available through the NCRIS Groundwater Database: http://groundwater.anu.edu.au. TCM was supported by an Australian Government Research Training Program (RTP) Scholarship. We thank the editor Eelco Rohling for handling this manuscript, and Ty Ferré as well as another anonymous reviewer for their positive reviews and encouraging comments.

\section{References}

Acworth, R. I., and T. Brain (2008), Calculation of barometric efficiency in shallow piezometers using water levels, atmospheric and earth tide data, Hydrogeology Journal, 16(8), 1469-1481, doi:10.1007/s10040-008-0333-y.

Acworth, R. I., G. C. Rau, A. M. McCallum, M. S. Andersen, and M. O. Cuthbert (2015a), Understanding connected surface-water/groundwater systems using Fourier analysis of daily and sub-daily head fluctuations, Hydrogeology Journal, 23(1), 143-159, doi:10.1007/ s10040-014-1182-5.

Acworth, R. I., W. A. Timms, B. F. Kelly, D. E. Mcgeeney, T. J. Ralph, Z. T. Larkin, and G. C. Rau (2015b), Late Cenozoic paleovalley fill sequence from the Southern Liverpool Plains, New South Wales-implications for groundwater resource evaluation, Australian Journal of Earth Sciences, 62(6), 657-680, doi:10.1080/08120099.2015.1086815.

Acworth, R. I., L. J. S. Halloran, G. C. Rau, M. O. Cuthbert, and T. L. Bernardi (2016), An objective frequency domain method for quantifying confined aquifer compressible storage using Earth and atmospheric tides, Geophysical Research Letters, 43(22), 611-671, doi: 10.1002/2016GL071328. 
Acworth, R. I., G. C. Rau, L. J. S. Halloran, and W. A. Timms (2017), Vertical groundwater storage properties and changes in confinement determined using hydraulic head response to atmospheric tides, Water Resources Research, 53(4), 2983-2997, doi:10.1002/2016WR020311.

Aeschbach-Hertig, W., and T. Gleeson (2012), Regional strategies for the accelerating global problem of groundwater depletion, Nature Geoscience, 5(12), 853-861, doi:10.1038/ngeo1617.

Agnew, D. C. (1986), Strainmeters and tiltmeters, Reviews of Geophysics, 24(3), 579-624, doi: 10.1029/RG024i003p00579.

Agnew, D. C. (2010), Earth Tides, Geodesy: Treatise on Geophysics, p. 163.

Aiton, E. J. (1955), The contributions of Newton, Bernoulli and Euler to the theory of the tides, Annals of Science, 11(3), 206-223, doi:10.1080/00033795500200215.

Allègre, V., E. E. Brodsky, L. Xue, S. M. Nale, B. L. Parker, and J. A. Cherry (2016), Using earth-tide induced water pressure changes to measure in situ permeability: A comparison with long-term pumping tests, Water Resources Research, 52(4), 3113-3126, doi: 10.1002/2015WR017346.

Alley, W. M. (2002), Flow and Storage in Groundwater Systems, Science, 296(5575), 19851990, doi:10.1126/science.1067123.

Alley, W. M., and L. F. Konikow (2015), Bringing GRACE Down to Earth, Groundwater, 53(6), 826-829, doi:10.1111/gwat.12379.

Ananthakrishnan, R., J. A. Maliekal, and S. S. Aralikatti (1984), Atmospheric Tidal Oscillations; Part 1. Historical Development, Indian Institute of Tropical Meteorology, 53(18).

Bertuzzi, R. (2014), Sydney sandstone and shale parameters for tunnel design, Australian Geomechanics Journal, 49(1), 1-39.

Bertuzzi, R., and P. J. N. Pells (2002), Geotechnical parameters of Sydney sandstone and shale, Australian Geomechanics, 37(5), 41-54.

Bierkens, M. F. P. (2015), Global hydrology 2015: State, trends, and directions, Water Resources Research, 51(7), 4923-4947, doi:10.1002/2015WR017173.

Binley, A., S. S. Hubbard, J. A. Huisman, A. Revil, D. A. Robinson, K. Singha, and L. D. Slater (2015), The emergence of hydrogeophysics for improved understanding of subsurface processes over multiple scales, Water Resources Research, 51(6), 3837-3866, doi: 10.1002/2015WR017016.

Biot, M. A. (1941), General theory of three-dimensional consolidation, Journal of Applied Physics, 12(2), 155-164, doi:10.1063/1.1712886.

Boy, J. P., R. Ray, and J. Hinderer (2006), Diurnal atmospheric tide and induced gravity variations, Journal of Geodynamics, 41(1-3), 253-258, doi:10.1016/j.jog.2005.10.010.

Bredehoeft, J. D. (1967), Response of well-aquifer systems to Earth tides, Journal of Geophysical Research, 72(12), 3075-3087, doi:10.1029/JZ072i012p03075.

Briciu, A. E. (2015), Wavelet analysis of lunar semidiurnal tidal influence on selected inland rivers across the globe, Scientific Reports, 4(1), 4193, doi:10.1038/srep04193.

Büllesfeld, F. J. (1985), Ein Beitrag zur harmonischen Darstellung des gezeitenerzeugenden Potentials, C: Deutsche Geodätische Kommission bei der Bayerischen, Beck.

Burbey, T. J., D. Hisz, L. C. Murdoch, and M. Zhang (2012), Quantifying fractured crystallinerock properties using well tests, earth tides and barometric effects, Journal of Hydrology, 414415, 317-328, doi:10.1016/j.jhydrol.2011.11.013.

Butler, J. J., W. Jin, G. A. Mohammed, and E. C. Reboulet (2011), New insights from well responses to fluctuations in barometric pressure, Ground Water, 49(4), 525-533, doi:10.1111/j. 1745-6584.2010.00768.x. 
Calvo, M., S. Rosat, and J. Hinderer (2018), Tidal Spectroscopy from a Long Record of Superconducting Gravimeters in Strasbourg (France), in International Association of Geodesy Symposia, vol. 147, pp. 131-136, doi:10.1007/1345\{\\}2016\{\\}223.

Cartwright, D. E., and A. C. Edden (1973), Corrected Tables of Tidal Harmonics, Geophysical Journal International, 33(3), 253-264, doi:10.1111/j.1365-246X.1973.tb03420.x.

Chapman, S. (1951), Atmospheric Tides and Oscillations, in Compendium of Meteorology, pp. 510-530, American Meteorological Society, Boston, MA, doi:10.1007/978-1-940033-70-9\{\_ \}43.

Chapman, S., and R. S. Lindzen (2012), Atmospheric tides: thermal and gravitational, Springer Science \& Business Media.

Chapman, S., and S. R. C. Malin (1970), Atmospheric Tides, Thermal and Gravitational: Nomenclature, Notation and New Results, Journal of the Atmospheric Sciences, 27(5), 707710, doi:10.1175/1520-0469(1970)027<0707:ATTAGN>2.0.CO;2.

Chapman, S., and K. Westfold (1956), A comparison of the annual mean solar and lunar atmospheric tides in barometric pressure, as regards their worldwide distribution of amplitude and phase, Journal of Atmospheric and Terrestrial Physics, 8(1-2), 1-23, doi:10.1016/ 0021-9169(56)90087-3.

Chapman, S., R. S. Lindzen, and S. Chapman (1969), Atmospheric tides, Space science reviews, 10(1), 3-188, doi:10.1007/978-94-010-3399-2.

Cheng, A. H.-D., and E. Detournay (1988), A direct boundary element method for plane strain poroelasticity, International Journal for Numerical and Analytical Methods in Geomechanics, 12(5), 551-572, doi:10.1002/nag.1610120508.

Clark, W. E. (1967), Computing the barometric efficiency of a well, Journal of the Hydraulics Division, 93(4), 93-98.

Cook, S. B., W. A. Timms, B. F. Kelly, and S. L. Barbour (2017), Improved barometric and loading efficiency estimates using packers in monitoring wells, Hydrogeology Journal, 25(5), 14511463, doi:10.1007/s10040-017-1537-9.

Cutillo, P. A., and J. D. Bredehoeft (2011), Estimating Aquifer Properties from the Water Level Response to Earth Tides, Ground Water, 49(4), 600-610, doi:10.1111/j.1745-6584.2010. 00778.x.

Darwin, G. H. (1899), The Tides and kindred phenomena in the solar system, HOUGHTON, MIFFLIN AND COMPANY.

David, K., W. Timms, S. Barbour, and R. Mitra (2017), Tracking changes in the specific storage of overburden rock during longwall coal mining, Journal of Hydrology, 553, 304-320, doi:10. 1016/j.jhydrol.2017.07.057.

Davis, D. R., and T. C. Rasmussen (1993), A comparison of linear regression with Clark's Method for estimating barometric efficiency of confined aquifers, Water Resources Research, 29(6), 1849-1854, doi:10.1029/93WR00560.

Deckers, J., K. Van Noten, M. Schiltz, T. Lecocq, and K. Vanneste (2018), Integrated study on the topographic and shallow subsurface expression of the Grote Brogel Fault at the boundary of the Roer Valley Graben, Belgium, Tectonophysics, 722, 486-506, doi:10.1016/j.tecto.2017. 11.019 .

der Kamp, G. (1972), Tidal fluctuations in a confined aquifer extending under the sea, in International Geological Congress, vol. 24, pp. 101-106.

Domenico, P. A. (1983), Determination of Bulk Rock Properties From Ground-water Level Fluctuations, Bulletin of the Association of Engineering Geologists, 20(3), 283-287, doi: 10.2113/gseegeosci.xx.3.283. 
Domenico, P. A., and F. W. Schwartz (1997), Physical and Chemical Hydrogeology, 2nd ed., 528 pp., John Wiley \& Sons, Inc.

Doodson, A. T. (1921), The Harmonic Development of the Tide-Generating Potential, Proceedings of the Royal Society A: Mathematical, Physical and Engineering Sciences, 100(704), 305329, doi:10.1098/rspa.1921.0088.

Dziewonski, A. M., and D. L. Anderson (1981), Preliminary reference Earth model, Physics of the Earth and Planetary Interiors, 25(4), 297-356, doi:10.1016/0031-9201(81)90046-7.

Famiglietti, J. S. (2014), The global groundwater crisis, Nature Climate Change, 4(11), 945-948, doi:10.1038/nclimate2425.

Farrell, W. E. (1972), Deformation of the Earth by surface loads, Reviews of Geophysics, 10(3), 761, doi:10.1029/RG010i003p00761.

Ferris, J. G. (1952), Cyclic fluctuations of water level as a basis for determining aquifer transmissibility, Tech. rep.

Fetter, C. (2000), Applied hydrogeology, 4th ed., Prentice Hall, doi:doi:0-13-088239-9.

Foster, S. S. D., and P. J. Chilton (2003), Groundwater: the processes and global significance of aquifer degradation, Philosophical Transactions of the Royal Society B: Biological Sciences, 358(1440), 1957-1972, doi:10.1098/rstb.2003.1380.

Galloway, D. L., and T. J. Burbey (2011), Review: Regional land subsidence accompanying groundwater extraction, Hydrogeology Journal, 19(8), 1459-1486, doi:10.1007/ s10040-011-0775-5.

Galvin, J. (2016), Ground Engineering - Principles and Practices for Underground Coal Mining, 684 pp., Springer International Publishing, Cham, doi:10.1007/978-3-319-25005-2.

Geertsma, J. (1966), Problems fo rock mechanics in petroleum production engineering, in Proceedings of the First Congress of International Society of Rock Mechanics, vol. 1, pp. 585-594, International Society for Rock Mechanics.

George, W. O., and F. E. Romberg (1951), Tide-producing forces and artesian pressures, Transactions, American Geophysical Union, 32(3), 369, doi:10.1029/TR032i003p00369.

Gibson, R. E. (1963), An analysis of system flexibility and its effect on time-lag in pore-water pressure measurements, Geotechnique, 13(1), 1-11.

Gleeson, T., Y. Wada, M. F. P. Bierkens, and L. P. H. van Beek (2012), Water balance of global aquifers revealed by groundwater footprint, Nature, 488(7410), 197-200, doi:10.1038/ nature 11295 .

Gleeson, T., K. M. Befus, S. Jasechko, E. Luijendijk, and M. B. Cardenas (2016), The global volume and distribution of modern groundwater, Nature Geoscience, 9(2), 161-167, doi:10. 1038/ngeo2590.

Gonthier, G. (2003), A Graphical Method for Estimation of Barometric Efficiency from Continuous Data - Concepts and Application to a Site in the Piedmont, Air Force Plant 6, Marietta, Georgia, Tech. rep., US Geological Survey, doi:10.3133/sir20075111.

Hann, J. v. (1889), Untersuchungen über die tägliche Oscillation des Barometers, Denkschriften der Kaiserlichen Akademie der Wissenschaften in Wien, 55, 49-121.

Harrington, G., P. Cook, and N. W. Commission (2011), Mechanical loading and unloading of confined aquifers: implications for the assessment of long-term trends in potentiometric levels, Tech. rep., Canberra.

Hart, D. J., and H. F. Wang (1995), Laboratory measurements of a complete set of poroelastic moduli for Berea sandstone and Indiana limestone, Journal of Geophysical Research: Solid Earth, 100(B9), 17,741-17,751, doi:10.1029/95JB01242. 
Hart, R. H. G., M. T. Gladwin, R. L. Gwyther, D. C. Agnew, and F. K. Wyatt (1996), Tidal calibration of borehole strain meters: Removing the effects of small-scale inhomogeneity, Journal of Geophysical Research: Solid Earth, 101(B11), 25,553-25,571, doi:10.1029/96JB02273.

Hartmann, T., and H.-G. Wenzel (1995), The HW95 tidal potential catalogue, Geophysical Research Letters, 22(24), 3553-3556, doi:10.1029/95GL03324.

Havin, V., and B. Jöricke (1994), The Uncertainty Principle in Harmonic Analysis, vol. 28, xii-543 pp., Springer Berlin Heidelberg, Berlin, Heidelberg, doi:10.1007/978-3-642-78377-7.

Hendry, M. T., L. A. Smith, and M. J. Hendry (2018), Analysis of measured pore pressure response to atmospheric pressure changes to evaluate small-strain moduli: methodology and case studies, Canadian Geotechnical Journal, 55(9), 1248-1256, doi:10.1139/cgj-2016-0584.

Hobbs, P. J., and J. H. Fourie (2000), Earth-tide and barometric influences on the potentiometric head in a dolomite aquifer near the Vaal River Barrage, South Africa, Water SA, 26(3), 353360.

Hsieh, P. A., J. D. Bredehoeft, and J. M. Farr (1987), Determination of aquifer transmissivity from Earth tide analysis, Water Resources Research, 23(10), 1824-1832, doi:10.1029/ WR023i010p01824.

Hsieh, P. A., J. D. Bredehoeft, and S. A. Rojstaczer (1988), Response of well aquifer systems to Earth tides: Problem revisited, Water Resources Research, 24(3), 468-472, doi:10.1029/ WR024i003p00468.

Hussein, M. E., N. E. Odling, and R. A. Clark (2013), Borehole water level response to barometric pressure as an indicator of aquifer vulnerability, Water Resources Research, 49(10), 7102-7119, doi:10.1002/2013WR014134.

IGETS (2018), Software tools.

Jacob, C. E. (1939), Fluctuations in artesian pressure produced by passing railroad-trains as shown in a well on Long Island, New York, Transactions, American Geophysical Union, 20(4), 666, doi:10.1029/TR020i004p00666.

Jacob, C. E. (1940), On the flow of water in an elastic artesian aquifer, Eos, Transactions American Geophysical Union, 21(2), 574-586.

Jasechko, S., D. Perrone, K. M. Befus, M. Bayani Cardenas, G. Ferguson, T. Gleeson, E. Luijendijk, J. J. McDonnell, R. G. Taylor, Y. Wada, and J. W. Kirchner (2017), Global aquifers dominated by fossil groundwaters but wells vulnerable to modern contamination, Nature Geoscience, 10(6), 425-429, doi:10.1038/ngeo2943.

Jorgensen, D. G. (1980), Relationships between basic soils-engineering equations and basic ground-water flow equations, Tech. rep., doi:10.3133/wsp2064.

Keys, W. S. (1989), Borehole Geophysics Applied to Ground-Water Investigations, National Water Well Association, 6375 Riverside Drive, Dublin, $\mathrm{OH} 43017$, USA.

Klönne, F. (1880), Die periodischen Schwankungen des Wasserspiegels in den inundierten Kohlenschachten von Dux in der Periode, Wien, Mathematisch-Naturwlssenschaftllchen Classe, 8(1), 1-5.

Krásná, H., J. Böhm, and H. Schuh (2013), Tidal Love and Shida numbers estimated by geodetic VLBI, Journal of Geodynamics, 70, 21-27, doi:10.1016/j.jog.2013.05.001.

Kruseman, G. P., and N. A. de Ridder (1990), Analysis and Evaluation of Pumping Test Data, Tech. Rep. 47, International Institute for Land Reclamation and Improvement, P.O. Box 45, 6700 AA Wageningen, The Netherlands, 1994.

Kudryavtsev, S. M. (2004), Improved harmonic development of the Earth tide-generating potential, Journal of Geodesy, 77(12), 829-838, doi:10.1007/s00190-003-0361-2. 
Lai, G., H. Ge, and W. Wang (2013), Transfer functions of the well-aquifer systems response to atmospheric loading and Earth tide from low to high-frequency band, Journal of Geophysical Research: Solid Earth, 118(5), 1904-1924, doi:10.1002/jgrb.50165.

Latychev, K., J. X. Mitrovica, M. Ishii, N.-H. Chan, and J. L. Davis (2009), Body tides on a 3-D elastic earth: Toward a tidal tomography, Earth and Planetary Science Letters, 277(1-2), 8690, doi:10.1016/j.epsl.2008.10.008.

Li, H., and J. J. Jiao (2001), Tide-induced groundwater fluctuation in a coastal leaky confined aquifer system extending under the sea, Water Resources Research, 37(5), 1165-1171, doi: 10.1029/2000WR900296.

Longuevergne, L., J. P. Boy, N. Florsch, D. Viville, G. Ferhat, P. Ulrich, B. Luck, and J. Hinderer (2009), Local and global hydrological contributions to gravity variations observed in Strasbourg, Journal of Geodynamics, 48(3-5), 189-194, doi:10.1016/j.jog.2009.09.008.

Love, A. E. H. (1911), Some problems of geodynamics, 220 pp., Cambridge University Press.

Masoumi, H., K. J. Douglas, and A. R. Russell (2016), A Bounding Surface Plasticity Model for Intact Rock Exhibiting Size-Dependent Behaviour, Rock Mechanics and Rock Engineering, 49(1), 47-62, doi:10.1007/s00603-015-0744-8.

Mehnert, E., A. Valocchi, M. Heidari, S. Kapoor, and P. Kumar (1999), Estimating Transmissivity from the Water Level Fluctuations of a Sinusoidally Forced Well, Ground Water, 37(6), 855860, doi:10.1111/j.1745-6584.1999.tb01184.x.

Meinzer, O. E. (1928), Compressibility and elasticity of artesian aquifers, Economic Geology, 23(3), 263-291, doi:10.2113/gsecongeo.23.3.263.

Meinzer, O. E. (1939), Ground water in the United States, a summary of ground-water conditions and resources, utilization of water from wells and springs, methods of scientific investigation, and literature relating to the subject, Tech. rep., U.S. G.P.O., doi:10.3133/wsp836D.

Meinzer, O. E., and H. A. Hard (1925), The artesian water supply of the Dakota sandstone in North Dakota, with special reference to the Edgeley quadrangle: Chapter E in Contributions to the hydrology of the United States, 1923-1924, Tech. rep.

Melchior, P. (1974), Earth tides, Geophysical Surveys, 1(3), 275-303, doi:10.1007/BF01449116.

Melchior, P. J. (1983), The tides of the planet earth, Pergamon Press.

Merriam, J. B. (1992), An ephemeris for gravity tide predictions at the nanogal level, Geophysical Journal International, 108(2), 415-422, doi:10.1111/j.1365-246X.1992.tb04624.x.

Merritt, M. L. (2004), Estimating hydraulic properties of the Floridan Aquifer System by analysis of earth-tide, ocean-tide, and barometric effects, Collier and Hendry Counties, Florida, Tech. rep., doi:10.3133/wri034267.

Munk, W., and G. J. F. MacDonald (1960), The rotation of the earth, a geophysical discussion: London.

Narasimhan, T. N., B. Y. Kanehiro, and P. A. Witherspoon (1984), Interpretation of Earth tide response of three deep, confined aquifers, Journal of Geophysical Research: Solid Earth, 89(B3), 1913-1924, doi:10.1029/JB089iB03p01913.

Naylor, R. (2007), Galileo's Tidal Theory, Isis, 98(1), 1-22, doi:10.1086/512829.

Norum, D. I., and J. N. Luthin (1968), The effects of entrapped air and barometric fluctuations on the drainage of porous mediums, Water Resources Research, 4(2), 417-424, doi:10.1029/ WR004i002p00417.

Odling, N., R. Perulero Serrano, M. Hussein, M. Riva, and A. Guadagnini (2015), Detecting the vulnerability of groundwater in semi-confined aquifers using barometric response functions, Journal of Hydrology, 520, 143-156, doi:10.1016/j.jhydrol.2014.11.016. 
Palciauskas, V. V., and P. A. Domenico (1989), Fluid pressures in deforming porous rocks, Water Resources Research, 25(2), 203-213, doi:10.1029/WR025i002p00203.

Palumbo, A. (1998), Atmospheric tides, Journal of Atmospheric and Solar-Terrestrial Physics, 60(3), 279-287, doi:10.1016/S1364-6826(97)00078-3.

Price, M. (2009), Barometric water-level fluctuations and their measurement using vented and non-vented pressure transducers, Quarterly Journal of Engineering Geology and Hydrogeology, 42(2), 245-250, doi:10.1144/1470-9236/08-084.

Pugh, D., and P. Woodworth (2014), Sea-Level Science, 1-395 pp., Cambridge University Press, Cambridge, doi:10.1017/CBO9781139235778.

Rahi, K. A., and T. Halihan (2013), Identifying aquifer type in fractured rock aquifers using harmonic analysis, GroundWater, 51(1), 76-82, doi:10.1111/j.1745-6584.2012.00925.x.

Rasmussen, T. C., and L. A. Crawford (1997), Identifying and Removing Barometric Pressure Effects in Confined and Unconfined Aquifers, Ground Water, 35(3), 502-511, doi:10.1111/j. 1745-6584.1997.tb00111.x.

Rau, G. C. (2018), PyGTide: A Python module and wrapper for ETERNA PREDICT to compute synthetic model tides on Earth, doi:10.5281/zenodo.1346260.

Rau, G. C., R. I. Acworth, L. J. S. Halloran, W. A. Timms, and M. O. Cuthbert (2018), Quantifying Compressible Groundwater Storage by Combining Cross-Hole Seismic Surveys and Head Response to Atmospheric Tides, Journal of Geophysical Research: Earth Surface, 123(8), 1910-1930, doi:10.1029/2018JF004660.

Ray, R. D., and R. M. Ponte (2003), Barometric tides from ECMWF operational analyses, $A n$ nales Geophysicae, 21(8), 1897-1910, doi:10.5194/angeo-21-1897-2003.

Rice, J. R., and M. P. Cleary (1976), Some basic stress diffusion solutions for fluid-saturated elastic porous media with compressible constituents, Reviews of Geophysics, 14(2), 227-241, doi:10.1029/RG014i002p00227.

Ritzi, R. W., S. Sorooshian, and P. A. Hsieh (1991), The estimation of fluid flow properties from the response of water levels in wells to the combined atmospheric and Earth tide forces, Water Resources Research, 27(5), 883-893, doi:10.1029/91WR00070.

Robinson, E. S., and R. T. Bell (1971), Tides in confined well-aquifer systems, Journal of Geophysical Research, 76(8), 1857-1869, doi:10.1029/JB076i008p01857.

Robinson, T. W. (1939), Earth-tides shown by fluctuations of water-levels in wells in New Mexico and lowa, Transactions, American Geophysical Union, 20(4), 656, doi:10.1029/ TR020i004p00656.

Rojstaczer, S. (1988a), Intermediate Period Response of Water Levels in Wells To Crustal Strain: Sensitivity and Noise Level, Journal of Geophysical Research, 93634(10), 619-13.

Rojstaczer, S. (1988b), Determination of fluid flow properties from the response of water levels in wells to atmospheric loading, Water Resources Research, 24(11), 1927-1938, doi:10.1029/ WR024i011p01927.

Rojstaczer, S., and D. C. Agnew (1989), The influence of formation material properties on the response of water levels in wells to Earth tides and atmospheric loading, Journal of Geophysical Research, 94(B9), 12,403, doi:10.1029/JB094iB09p12403.

Roosbeek, F. (1996), RATGP95: a harmonic development of the tide-generating potential using an analytical method, Geophysical Journal International, 126(1), 197-204, doi:10.1111/j. 1365-246X.1996.tb05278.x.

Siebert, M. (1961), Atmospheric Tides, in Advances in Geophysics, vol. 7, pp. 105-187, Elsevier, doi:10.1016/S0065-2687(08)60362-3. 
Smerdon, B. D., L. A. Smith, G. A. Harrington, W. P. Gardner, C. D. Piane, and J. Sarout (2014), Estimating the hydraulic properties of an aquitard from in situ pore pressure measurements, Hydrogeology Journal, 22(8), 1875-1887, doi:10.1007/s10040-014-1161-x.

Smith, L. A., G. van der Kamp, and M. Jim Hendry (2013), A new technique for obtaining highresolution pore pressure records in thick claystone aquitards and its use to determine in situ compressibility, Water Resources Research, 49(2), 732-743, doi:10.1002/wrcr.20084.

Spane, F. A. (2002), Considering barometric pressure in groundwater flow investigations, Water Resources Research, 38(6), 14-1, doi:10.1029/2001WR000701.

Standish, E. M. (1998), JPL Planetary and Lunar Ephemerides, DE405/LE405, Tech. rep., NASA Jet Propulsion Laboratory.

Tamura, Y. (1987), A harmonic development of the tide-generating potential, Bulletin d'Informations des Marées Terrestres, 99, 6813-6855.

Tamura, Y. (1993), Additional terms to the tidal harmonic tables, in Proceedings 12th International Symposium on Earth Tides, pp. 345-350, Science Press, Beijing/New York, Beijing.

Taylor, R. G., B. Scanlon, P. Döll, M. Rodell, R. van Beek, Y. Wada, L. Longuevergne, M. Leblanc, J. S. Famiglietti, M. Edmunds, L. Konikow, T. R. Green, J. Chen, M. Taniguchi, M. F. P. Bierkens, A. MacDonald, Y. Fan, R. M. Maxwell, Y. Yechieli, J. J. Gurdak, D. M. Allen, M. Shamsudduha, K. Hiscock, P. J.-F. Yeh, I. Holman, and H. Treidel (2013), Ground water and climate change, Nature Climate Change, 3(4), 322-329, doi:10.1038/nclimate1744.

Theis, C. V. (1935), The relation between the lowering of the Piezometric surface and the rate and duration of discharge of a well using ground-water storage, Eos, Transactions American Geophysical Union, 16(2), 519-524.

Thomson, S. W. (1881), The tide gauge, tidal harmonic analyser, and tide predicter., Minutes of the Proceedings of the Institution of Civil Engineers, 65(1881), 2-25, doi:10.1680/imotp.1881. 22262.

Timms, W. A., and R. I. Acworth (2005), Propagation of pressure change through thick clay sequences: an example from Liverpool Plains, NSW, Australia, Hydrogeology Journal, 13(5-6), 858-870, doi:10.1007/s10040-005-0436-7.

Van Camp, M., and P. Vauterin (2005), Tsoft: graphical and interactive software for the analysis of time series and Earth tides, Computers \& Geosciences, 31(5), 631-640, doi:10.1016/j. cageo.2004.11.015.

Van Camp, M., O. de Viron, A. Watlet, B. Meurers, O. Francis, and C. Caudron (2017), Geophysics From Terrestrial Time-Variable Gravity Measurements, Reviews of Geophysics, 55(4), 938-992, doi:10.1002/2017RG000566.

Van Dam, T., and R. D. Ray (2010), S1 and S2 Atmospheric Tide Loading Effects for Geodetic Applications, http://geophy.uni.lu/ggfc-atmosphere/tide-loading-calculator.html.

van der Kamp, G. (2001), Methods for determining the in situ hydraulic conductivity of shallow aquitards - An overview, Hydrogeology Journal, 9(1), 5-16, doi:10.1007/s100400000118.

van der Kamp, G., and J. E. Gale (1983), Theory of earth tide and barometric effects in porous formations with compressible grains, Water Resources Research, 19(2), 538-544, doi:10.1029/ WR019i002p00538.

van der Kamp, G., and R. Schmidt (2017), Review: Moisture loading-the hidden information in groundwater observation well records, Hydrogeology Journal, 25(8), 2225-2233, doi:10.1007/ s10040-017-1631-z.

Venedikov, A. P., and R. Vieira (2004), Guidebook for the practical use of the computer program VAV-version 2003, Bulletin d'Informations des Marées Terrestres, 139, 11,037-11,102.

Verruijt, A. (2013), Theory and problems of poroelasticity, Delft University of Technology, The Netherlands. 
Vinogradov, E., E. Gorbunova, A. Besedina, and N. Kabychenko (2018), Earth Tide Analysis Specifics in Case of Unstable Aquifer Regime, Pure and Applied Geophysics, 175(5), 17831792, doi:10.1007/s00024-017-1585-z.

Wada, Y., L. P. Van Beek, C. M. Van Kempen, J. W. Reckman, S. Vasak, and M. F. Bierkens (2010), Global depletion of groundwater resources, Geophysical Research Letters, 37(20), doi: 10.1029/2010GL044571.

Wang, H. F. (2001), Theory of Linear Poroelasticity with Applications to Geomechanics and Hydrogeology, 304 pp., Princeton University Press.

Weeks, E. P. (1978), Field determination of vertical permeability to air in the unsaturated zone, 1051, 41 pp., Department of the Interior, Geological Survey.

Weeks, E. P. (1979), Barometric fluctuations in wells tapping deep unconfined aquifers, Water Resources Research, 15(5), 1167-1176, doi:10.1029/WR015i005p01167.

Wenzel, H.-G. (1996), The nanogal software: Earth tide data processing package ETERNA 3.30, Bulletin d'Informations Mareés Terrestres, 124.

Werner, A. D., M. Bakker, V. E. Post, A. Vandenbohede, C. Lu, B. Ataie-Ashtiani, C. T. Simmons, and D. A. Barry (2013), Seawater intrusion processes, investigation and management: Recent advances and future challenges, Advances in Water Resources, 51, 3-26, doi: 10.1016/j.advwatres.2012.03.004.

Xi, Q. W., and T. H. Hou (1987), A new complete development of the tide-generating potential for the epoch J2000. 0, Acta Geophysica Sinica, 30(4), 349-362.

$\mathrm{Xu}, \mathrm{J}$., H. Sun, and B. Ducarme (2004), A global experimental model for gravity tides of the Earth, Journal of Geodynamics, 38(3-5), 293-306, doi:10.1016/j.jog.2004.07.003.

Xue, L., H.-B. Li, E. E. Brodsky, Z.-Q. Xu, Y. Kano, H. Wang, J. J. Mori, J.-L. Si, P. Jun-Ling, W. Zhang, G. Yang, Z.-M. Sun, and Y. Huang (2013), Continuous Permeability Measurements Recor Healing Inside the Wenchuan Earthquake Fault Zone, Science, 340(6140), 1555-9, doi:10.1126/science.1229223.

Xue, L., E. E. Brodsky, J. Erskine, P. M. Fulton, and R. Carter (2016), A permeability and compliance contrast measured hydrogeologically on the San Andreas Fault, Geochemistry, Geophysics, Geosystems, 17(3), 858-871, doi:10.1002/2015GC006167.

Young, A. (1913), Tidal phenomena at inland boreholes near Caradock, Transactions of the Royal Society of South Africa, 3(1), 61-106.

Yu, C., J. M. Matray, J. Gonçalvès, D. Jaeggi, W. Gräsle, K. Wieczorek, T. Vogt, and E. Sykes (2017), Comparative study of methods to estimate hydraulic parameters in the hydraulically undisturbed Opalinus Clay (Switzerland), Swiss Journal of Geosciences, 110(1), 85-104, doi: 10.1007/s00015-016-0257-9.

Yuan, L., B. F. Chao, X. Ding, and P. Zhong (2013), The tidal displacement field at Earth's surface determined using global GPS observations, Journal of Geophysical Research: Solid Earth, 118(5), 2618-2632, doi:10.1002/jgrb.50159.

Zhang, C., R. Mitra, J. Oh, and B. Hebblewhite (2016), Analysis of Mining-induced Valley Closure Movements, Rock Mechanics and Rock Engineering, 49(5), 1923-1941, doi:10.1007/ s00603-015-0880-1.

Zhang, C., R. Mitra, J. Oh, I. Canbulat, and B. Hebblewhite (2018), Numerical analysis on mining-induced fracture development around river valleys, International Journal of Mining, Reclamation and Environment, 32(7), 463-485, doi:10.1080/17480930.2017.1293495. 